\title{
Numerical Evaluation of Shear Strength Degradation Mechanism Dependent on the Size Increase of RC Deep Beams with Height up to 1.5 Meter by Using 3D Rigid-Body-Spring-Method
}

\author{
$\mathrm{Li} \mathrm{Fu}^{1}$, Hikaru Nakamura ${ }^{2 *}$, Shunyuan $\mathrm{Chi}^{3}$, Yoshihito Yamamoto ${ }^{4}$ and Taito Miura ${ }^{5}$
}

Received 31 March 2021, accepted 2 December 2021

doi:10.3151/jact.19.1245

\begin{abstract}
The purpose of this paper is to clarify the mechanism of shear strength reduction for reinforced concrete deep beams with varying stirrup ratios, due to the beam size increase. Three Dimensional Rigid-Body-Spring-Method was the applied numerical tool. By using the simulation results of reinforced concrete deep beams with the effective depth smaller than $1500 \mathrm{~mm}$, the size dependence of each shear resistance component such as arch, beam and truss actions were investigated, along with the size dependence of localized information such as crack pattern, diagonal crack width and compressive stress. It was revealed that the size effect on shear strength results from the size dependence of the arch action, and the change of stirrup ratio does not show any inhibiting effects on it. The crucial reason for the size effect on the arch action is the size dependence of concrete compressive resultant on beam cross sections, and the critical diagonal crack width, which increases with beam size, is a key factor for the deterioration of concrete compressive strength and the capacity of compressive stress in struts. Moreover, it was found that the critical diagonal crack width not only affects the normalized shear strength, but also has influence on the post-peak behavior of deep beam.
\end{abstract}

\section{Introduction}

In recent years, the number of manufactured large scale reinforced concrete (RC) members is increasing, and such members are widely used in civil engineering structures. Corresponding to this trend, the size effect on the shear strength of an RC member represents an inevitable and important factor associated with the shear design.

Investigations of the size effect on the shear strength began with the studies of reinforced concrete (RC) slender beams (shear span to depth ratio, $a / d$, larger than 2.0 according to ACI 318M-14 (ACI 2015), and JSCE Standard Specifications for Concrete-Design (JSCE 2017), and its existence in such beams without shear reinforcement was experimentally demonstrated by

${ }^{1}$ Lecturer, School of Environment and Civil Engineering JiangNan University, No. 1800 Lihu Avenue, Wuxi, Jiangsu Province, 214122, China.

${ }^{2}$ Professor, Graduate School of Civil and Environmental Engineering, Nagoya University, Furo-cho, Chikusa-ku, Nagoya, 464-8603, Japan. *Corresponding author,

E-mail: hikaru@cc.nagoya-u.ac.jp

${ }^{3}$ Engineer, Global Company Railway Department, Pacific Consultants Co., Ltd, Kanda-Nishikicho 3-22, Chiyoda Ward, Tokyo, 101-8642, Japan.

${ }^{4}$ Professor, Department of Civil and Environmental Engineering, Hosei University, 2-33 Ichigaya-Tamachi, Shinjuku, Tokyo, 162-0843, Japan.

${ }^{5}$ Associate Professor, Graduate School of Civil and Environmental Engineering, Nagoya University, Furo-cho, Chikusa-ku, Nagoya, 464-8603, Japan.
Leonhardt and Walther (1962), Kani (1967), Iguro and Shioya (1985), Shioya et al. (1989), Lubell et al. (2004), and Tung and Tue (2016). These research works generally showed that the size effect is associated with the bigger diagonal crack widths in larger members, which was argued to affect the aggregate interlock contribution. Some studies attempted to establish the design formulas for the size effect in slender beams without shear reinforcement, based on the statistical analysis of experimental results (Zararis and Papadakis 2001; Bažant and Yu 2005a, 2005b). As for the effect of shear reinforcement, it was found from the experimental tests and numerical simulations that the arrangement of stirrups can effectively suppress or eliminate the size effect on the shear strength (Kuchma et al. 1998; Frosch 2000; Lubell et al. 2004; Yu and Bažant 2011). Based on the results, international design codes (Standard Specifications for Concrete-Design (JSCE 2017); Eurocode 2 (CEM 2014); GB 50010-2010 (MOHURD 2015) introduced the size effects depending on factors into the shear design for RC members, by using statistical analysis of experimental results.

To date, most investigations on the size effect and the corresponding designs are mainly based on the experimental results for slender members $(a / d>2.0)$. It is not clear whether the same mechanism and design formulas are suitable for the size dependence in deep members $(a / d<2.0)$, although the existence of the significant size dependence in deep beams was experimentally demonstrated (Walraven and Lehwalter 1994; Lertsrisakulrat et al. 2002; Teng et al. 1996; Tang and Tan 2004). ACI 318M-14 (ACI 2015) and fib Model Code 2010 (fib 2013) recommend to apply the strut-and-tie model to the shear design of deep members, but the size dependence 
is ignored, which is a rather vague rationalization.

Compared with the slender beams, the deep ones show some unique shear behaviors, which may lead to a distinct size effect mechanism: (1) a shear force in a cross section of a deep beam is more pronounced than the moment effect; (2) a shear resistance mechanism (which may be represented with the strut-and-tie model) and a shear failure mode (generally a compression failure of concrete in the vicinity of a loading point) differs from that of slender beams, in which the diagonal tension failure takes place soon after the diagonal crack occurrence; (3) the reinforcing effect provided by shear reinforcement is more complex and not consistent with the truss theory. With respect to the reason for the size effect in deep members, based on the experimental results for deep beams, Kosa et al. (2009) argued that it is caused by the reduction of the relative strut area with increasing beam depth, i.e., the localization trend of compression failure at the strut zone. Moreover, compared to slender beams, the obtained results indicated that the setting of stirrups almost had no influence on the size effect suppression. In summary, the number of studies about the size effect mechanism of the shear strength for RC deep beams is very small, and the discussions made up to now cannot make a full understanding of the mechanism, which is necessary for the improvement of the current shear design.

This paper aims to clarify the occurrence of shear strength degradation depending on the size increase for $\mathrm{RC}$ deep beams including the effect of stirrup arrangement, based on the Three Dimensional Rigid-Body-Spring-Method (3D RBSM) numerical approaches. The discussion focused on the size effect under $1500 \mathrm{~mm}$ effective depth. The 3D RBSM is a discrete method and has the advantages of reproducing crack propagation realistically, and enables visualization of the localized stress state in concrete material (Yamamoto et al. 2008, 2010).

In order to achieve the above goals, this paper is organized as follows: first the ability of the 3D RBSM to reproduce the shear failure behaviors of RC deep beams with and without shear reinforcement at large effective depth of $1000 \mathrm{~mm}$ was shown in Section 2 and Section
3. The size effect on the shear strength was quantitatively examined by conducting three groups of numerical analyses in Section 4 (the effective depths and stirrup ratios of the beams in each group ranged from 400 to $1500 \mathrm{~mm}$ and from 0.0 to $0.4 \%$, respectively). Whereas, the mechanism of the size effect was examined through the size dependence of each shear resistance component (beam, arch and truss actions, and concrete contribution to the beam action), and the corresponding localized information (crack pattern, diagonal crack width, and compressive stress in axial direction) in Section 5. The main conclusions are summarized in Section 6.

\section{Numerical method}

The 3D RBSM was applied as the primary tool in this study to analyze the fracture behavior of concrete, including softening and localization fractures. The method was applied to simulate various structural performances of concrete members, such as flexural and shear behaviors of beam, column and wall members. It succeeded in representing not only load-displacement relationships, but also localized cracking behavior (Gedik et al. 2011, 2012; Yamamoto et al. 2014; Fu et al. 2017a, 2017b). The brief outline of the 3D RBSM is described in this section.

\subsection{Modeling of concrete}

Concrete was modeled as an assemblage of rigid polyhedrons interconnected by springs at their boundary surfaces. Random geometry of rigid polyhedrons was generated by Voronoi random tessellation since crack initiation and propagation significantly depends on the mesh design (Fig. 1) (Yamamoto et al. 2008).

In the terms of a spring model, one normal and two tangential springs were set at each integration point located at the boundary surface of each two adjacent concrete particles. The response of springs can provide an insight into the interaction among concrete particles, and crack propagation can be reflected by the failure of springs or the relative displacement of two adjacent concrete particles. Three translational and three rotational degrees of freedom were defined at the nuclei that

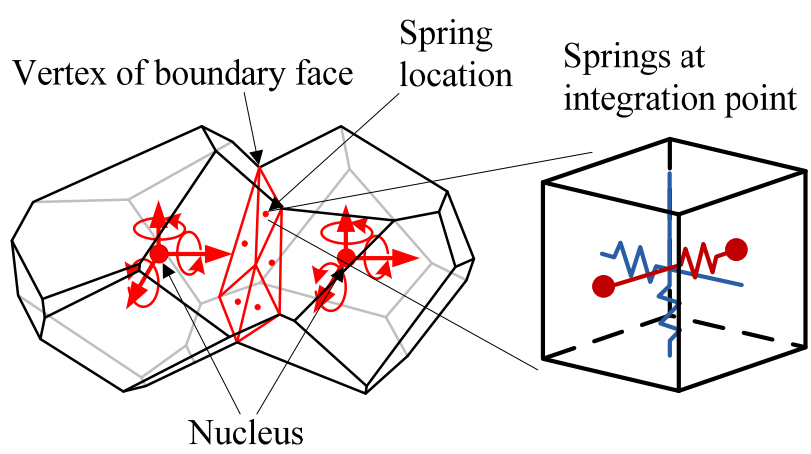

(a) Rigid-Body-Spring-Model

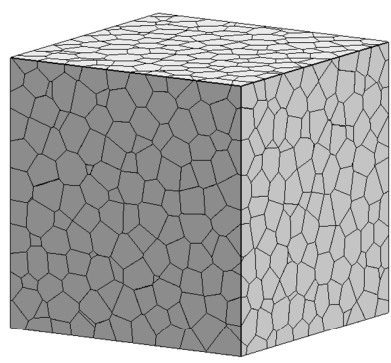

(b) Voronoi diagram

Fig. 1 3D RBSM for modeling of concrete. 
generate concrete particles.

The related constitutive models for tension, compression of normal springs and shear springs, were constructed in the form of uniaxial stress-strain relationships, and were validated by Yamamoto et al. (2008), as shown in Fig. 2. As for the typical hysteresis loops for cyclic loading analysis, the reloading paths of springs were assumed to first return to the starting point of a preceding unloading, and thereafter to run along the monotonic hysteretic curves. The detailed standard model parameters for normal and shear springs can be found in the previous work (Yamamoto et al. 2008), and their description is skipped herein.

\subsection{Modeling of reinforcement}

Steel reinforcement was generally modeled as a series of regular beam elements (Fig. 3). In a model, the beam element can be freely placed within a member, regardless of the concrete mesh design (Bolander and Hong 2002). Each beam element had six degrees of freedom,

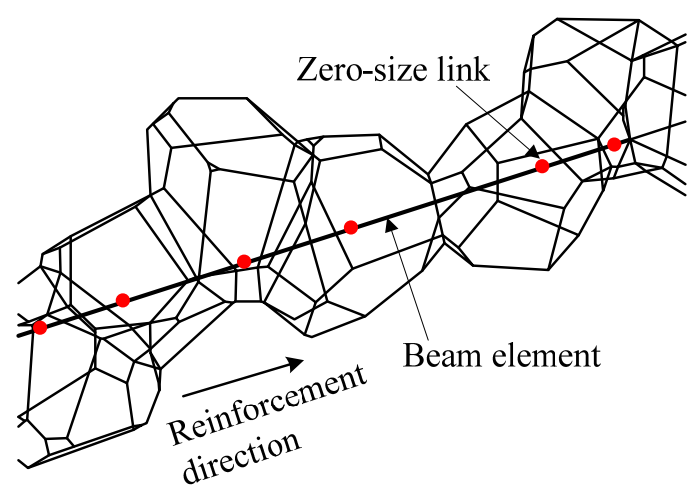

Fig. 3 Model of steel reinforcement. which is similar to concrete particles. The beam element was attached to concrete particles by means of a zero size link node. The link node can provide a load-transfer mechanism between the concrete particle and beam element, and each link node has three translational degrees of freedom, one parallel and two perpendicular to the axis of reinforcement.

With regard to the constitutive models, a bi-linear model shown in Fig. 4a was adopted for the stress-strain relationship of rebars. After reaching a yield strain, a stress in the rebar remains constant (yield stress). Crack development is strongly affected by the bond between concrete and the rebar link node. For the bond stress-strain relationship (Fig. 4b), up to the shear strength, the model proposed by Suga et al. (2001) was applied, while the post-peak behavior was described by the CEB-FIB Code Model 90 (fib 1990). The applicability of the bond stress-strain relationship to structural analysis of RC members was confirmed by several studies (Yamamoto et al. 2010, 2014).

\section{Validation of the numerical method}

Gedik et al. (2011, 2012) demonstrated that the 3D RBSM is capable of reproducing shear failure behaviors of RC deep beams with effective depth of $240 \mathrm{~mm}$ at varying shear span to depth ratios $(0.5 \leq a / d \leq 2.0)$ and stirrup ratios $\left(0.0 \% \leq \rho_{w} \leq 0.9 \%\right)$ with high accuracy. Fu et al. (2017b) confirmed that the 3D RBSM can reproduce the shear behavior of RC short beams $(a / d=2.35)$ with initial crack damage. Recently, Nakamura et al. (2018) validated the 3D RBSM in simulating the experimental results of shear failure behaviors for $\mathrm{RC}$ deep $(a / d=1.57)$ and slender beams $(a / d=3.14)$ with

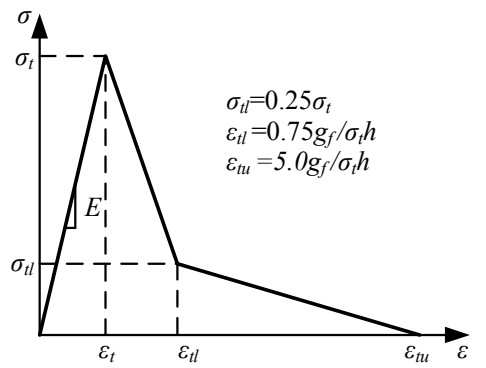

(a) Tensile model of normal spring

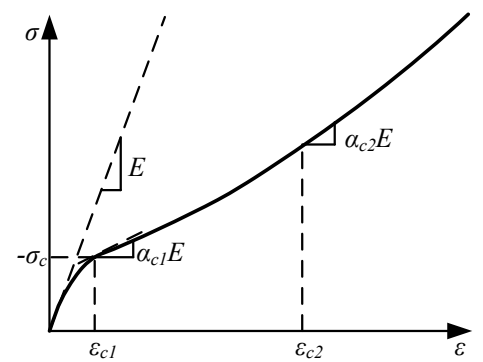

(b) Compression model of normal spring

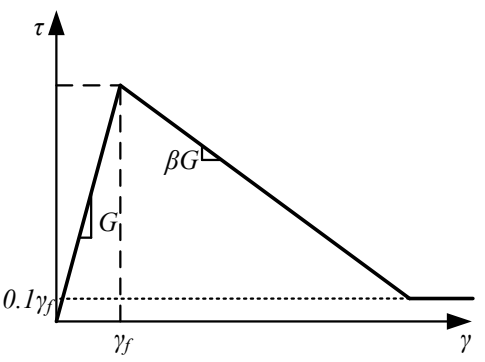

(c) Shear spring model

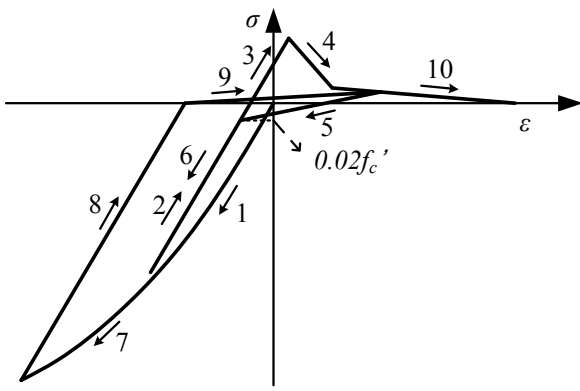

(d) Normal spring

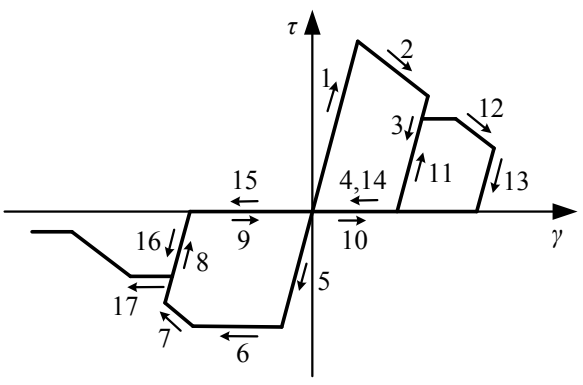

(e) Shear spring ( $\sigma=$ constant)

Fig. 2 Constitutive models for concrete according to Yamamoto et al. (2008, 2014). 
effective depths of $255 \mathrm{~mm}$, without stirrups and with the stirrup ratio of $0.28 \%$. It was shown that both the load-displacement relationships and crack propagations can be accurately simulated. Moreover, a series of simulations were carried out for beams having a wide range of shear span to depth ratios $(1.57 \leq a / d \leq 4.71)$ and stirrup ratios $\left(0.0 \% \leq \rho_{w} \leq 0.56 \%\right)$. The accuracy of the simulations was confirmed, and it was revealed that the shear failure mechanisms are related to the shear span to depth and stirrup ratios. However, the ability to apply the 3D RBSM for the evaluation of shear failure performance of large scale RC deep beams is still an unsolved issue. Therefore, by considering the large scale $\mathrm{RC}$ deep beams experimentally tested by Kosa et al.
(2009) and Kobayashi et al. (2005), the validation work was first carried out.

\subsection{An overview of experimentally tested beams}

With an intention to investigate the size effect on shear strength of RC deep beams, Kosa et al. (2009) conducted a four-point shear load test for a few groups of $\mathrm{RC}$ beams with shear span to depth ratios of 1.5 , with and without stirrups. Beams had the effective depths in a range from 400 to $1000 \mathrm{~mm}$.

In this paper, two beams with the effective depth of $1000 \mathrm{~mm}$ were selected for the simulation test, and their structural details are shown in Fig. 5. The relevant structural factors and the main material properties are

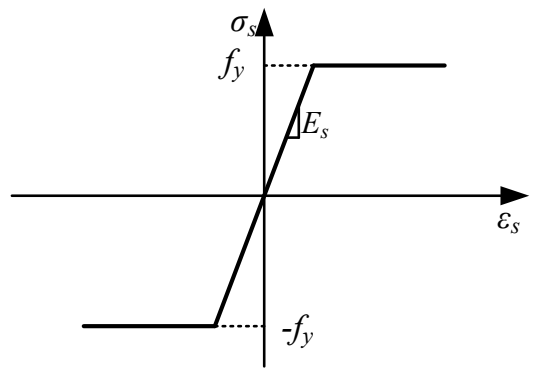

(a) Stress-strain relationship

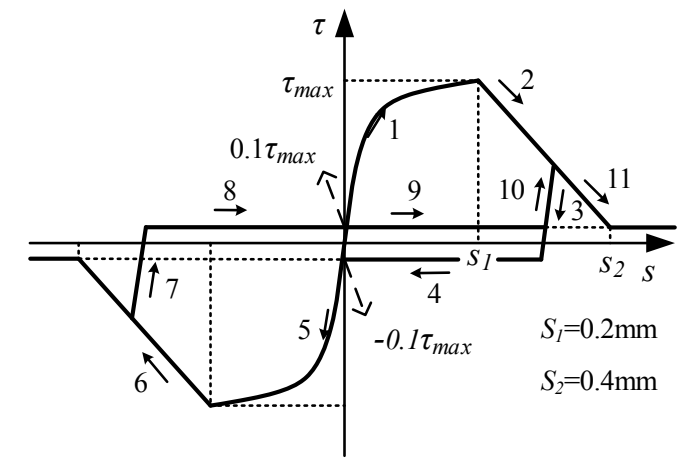

(b) Bond stress-slip relationship

Fig. 4 (a) Stress-strain and (b) bond stress-slip models for steel reinforcement.

Measuring bars

(D4)
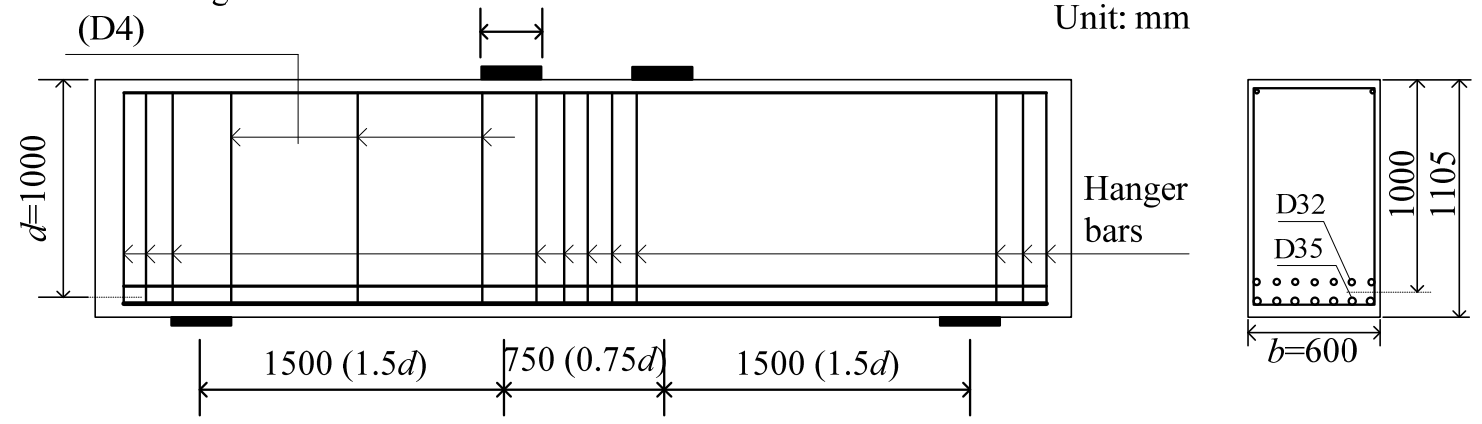

(a) Specimen without stirrups in failure span
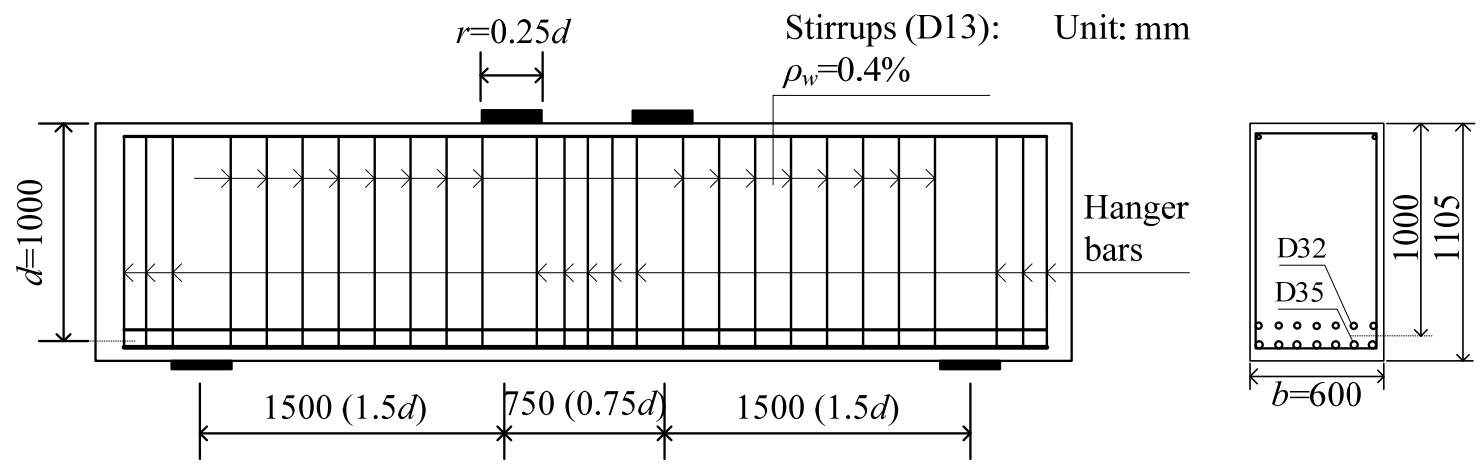

(b) Specimen with stirrups in failure span

Fig. 5 Design details of specimens for validation. 
Table 1 Structural factors and material properties of test specimens.

\begin{tabular}{|c|c|c|c|c|c|c|c|c|c|}
\hline \multirow[b]{2}{*}{ Specimen } & \multirow{2}{*}{$\begin{array}{c}\text { Shear } \\
\text { span to } \\
\text { depth } \\
\text { ratio } \\
\text { ald }\end{array}$} & \multirow[b]{2}{*}{$\begin{array}{c}\text { Loading plate } \\
\text { width-effective } \\
\text { depth ratio } \\
r / d\end{array}$} & \multicolumn{3}{|c|}{ Tensile reinforcement (SD 345) } & \multicolumn{3}{|c|}{ Stirrups } & \multirow{2}{*}{\begin{tabular}{|c|} 
Concrete \\
Compressive \\
strength \\
$f_{c}^{\prime}$ (MPa)
\end{tabular}} \\
\hline & & & $\begin{array}{c}\text { Tensile steel } \\
\text { ratio } \\
\rho_{t}(\%)\end{array}$ & $\begin{array}{c}\text { Cross } \\
\text { sectional area } \\
A_{s}\left(\mathrm{~mm}^{2}\right)\end{array}$ & $\begin{array}{c}\text { Yield } \\
\text { strength } \\
f_{s y}(\mathrm{MPa})\end{array}$ & $\begin{array}{l}\text { Stirrups } \\
\text { ratio } \\
\rho_{w}(\%)\end{array}$ & $\begin{array}{c}\text { Cross } \\
\text { sectional area } \\
A_{w}\left(\mathrm{~mm}^{2}\right)\end{array}$ & $\begin{array}{c}\text { Yield } \\
\text { strength } \\
f_{w y}(\mathrm{MPa})\end{array}$ & \\
\hline $\begin{array}{l}\text { Without stir- } \\
\text { rups }\end{array}$ & \multirow[t]{2}{*}{1.5} & \multirow[t]{2}{*}{0.25} & \multirow[t]{2}{*}{1.99} & \multirow{2}{*}{$\begin{array}{l}\text { D35: } 956 \\
\text { D32: } 794\end{array}$} & \multirow[t]{2}{*}{401.8} & 0.0 & - & - & 31.0 \\
\hline With stirrups & & & & & & 0.4 & D13: 387.1 & 347.2 & 28.7 \\
\hline
\end{tabular}

given in Table 1. Beams have a rectangular cross section configuration of $600 \mathrm{~mm} \times 1105 \mathrm{~mm}$, and the loading plate width to effective depth ratio $(r / d)$ of 0.25 . Seven D35 (35 mm in diameter) and seven D32 (32 mm in diameter) longitudinal steel bars were placed within two layers as tensile reinforcement, with a concrete cover thickness of $50 \mathrm{~mm}$, i.e., the tensile steel ratio $\left(\rho_{t}\right)$ was $1.99 \%$. D13 (13 $\mathrm{mm}$ in diameter) stirrups were placed longitudinally within the spacing of $135 \mathrm{~mm}$ for the specimen with stirrups, i.e., the stirrup ratio $\left(\rho_{w}\right)$ was $0.4 \%$ (Fig. 5b). In addition, three D4 (4 mm in diameter) round steel bars, used as strain measuring bars, were placed vertically in the one shear span of the specimen without stirrups (Fig. 5a), with an intention to have an insight into the localized vertical tensile strains in concrete (their effect on shear behavior was negligible). The above two beams were selected in this validation work since the capacity of the 3D RBSM simulating the shear behavior of beams with large height such as $1000 \mathrm{~mm}$ and the effect of shear reinforcement/stirrups can be validated. Furthermore, the crucial experimental records such as the load-displacement relationships (macro behavior) and crack patterns at the failure stage (localized behavior), which are necessary for the validation, were provided by Kosa et al. (2009) and Kobayashi et al. (2005). In addition, both beams exhibited localized shear compression failure in the vicinity of loading plates, resulting from the expansion of diagonal cracks along compressive struts, which is a common failure mode of RC deep beams.

\subsection{Numerical model}

The corresponding 3D RBSM models for the two beams were established according to the method discussed in Section 2 (Fig. 6). The average mesh size of $30 \mathrm{~mm}$ was adopted for the design of concrete part, and the appro- priateness of such a choice was confirmed in previous studies (Yamamoto et al. 2008; Fu et al. 2017a). The main material properties of concrete such as tensile strength, elastic modulus and fracture energy, were determined according to the estimation formulas published in Standard Specifications for Concrete-Design (JSCE 2017), by considering the experimental concrete compressive strength as an input. All tensile rebars and stirrups were modeled by beam elements with link nodes for the transfer of bond stress, as described in Section 2.2. However, bars used for vertical tensile strains measuring in the beam without stirrups and compression bars in both specimens were neglected since they had no effect on the mechanical behavior.

\subsection{Comparison of numerical and experimental results}

The experimental and numerical load-displacement relationships for the two beams are compared in Fig. 7. The initial stiffness and shear cracking loads obtained from the simulation are in a very good agreement with the experiment. After the occurrence of critical diagonal cracks, the stiffness of beams was significantly reduced, although the numerical curves are slightly steeper than the experimentally obtained ones. Numerical results present clear peak loads, and due to the contribution of stirrups, the beam with stirrups reaches higher load capacity, which agrees well with the experiment. For both beams, the peak loads from the simulation are slightly higher than the ones from the experimental results. Possible reasons are that some concrete mechanical properties were calculated by prediction formulas in design codes, and the large scale beams in the experiment were susceptible to temperature and shrinkage stresses during the early age stage, which was not taken into account in the numerical analyses. Finally, the slopes of curves at

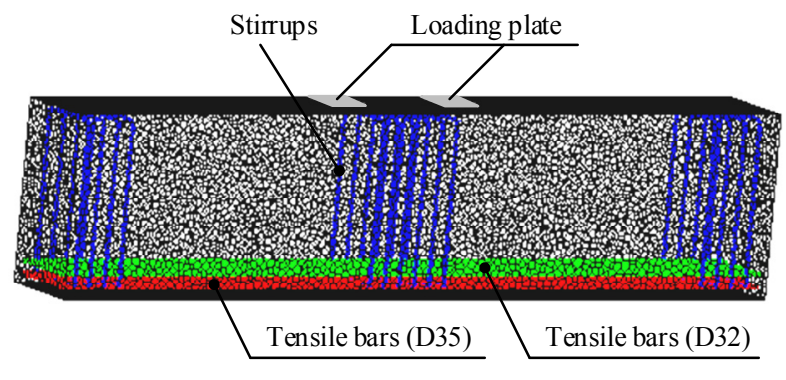

(a) Specimen without stirrups in failure span $\left(\rho_{w}=0.0 \%\right)$

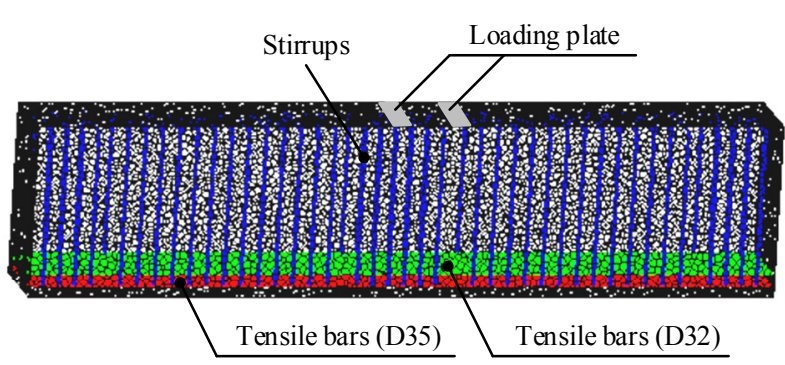

(b) Specimen with stirrups in failure span $\left(\rho_{w}=0.4 \%\right)$

Fig. 6 Mathematical models. 
post-peak stage are also very similar to the curves from the experiments, including a more gradual decline trend due to the confinement of stirrups.

Figure 8 illustrates crack patterns of the two beams at the post-peak stages obtained from the experiment and simulation (at the central longitudinal section). In simulation, the crack width is defined as the relative displacement between the centers of two adjacent concrete particles along the direction perpendicular to their boundary surface. The advantages of the 3D RBSM are demonstrated, and the numerical results display dispersed cracks similar to the experimentally obtained ones. A few diagonal cracks are formed and grown in the shear span of the beam without stirrups, and the splitting diagonal crack propagates to the position of the loading plate (Fig. 8a). Attributed to the effect of stirrups, a greater number of diagonal cracks form in the beam with stirrups, and the width of each diagonal crack is effectively confined, compared to the beam without stirrups. At the ultimate stage, the critical diagonal crack significantly develops (Fig. 8b) and the crushing of concrete nearby loading plate leads to failure. Same shear failure behaviors were observed in the experiments, but more cracks formed in the vicinity of tensile

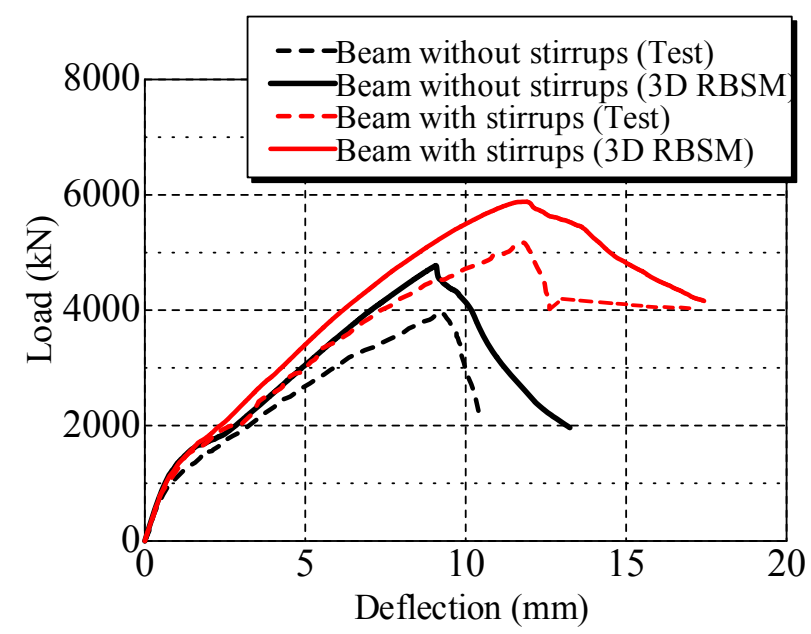

Fig. 7 Load-displacement relationships (experimental results refer to Kobayashi et al. 2005).

$0.1 \mathrm{~mm}=2.0 \mathrm{~mm}$
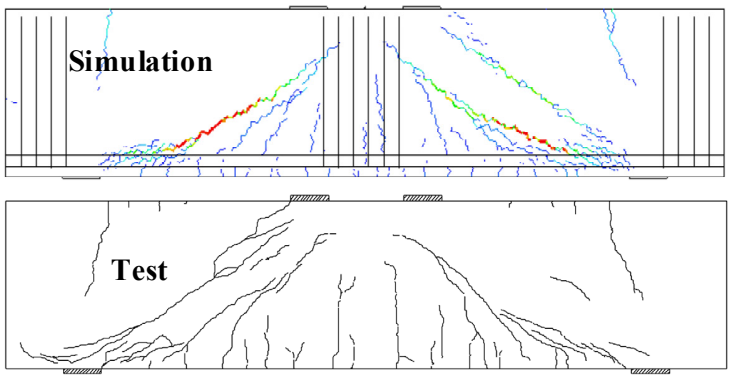

(a) Stirrups ratio $\rho_{w}=0.0 \%$ rebars in the simulations, due to the no consideration of temperature and shrinkage stresses at early age stages. Probably because of the denser distribution of cracks, slightly higher beam stiffness and peak loads after diagonal cracking occur in the simulation.

In conclusion, the 3D RBSM is suitable for the accurate simulation of the shear behaviors for $\mathrm{RC}$ deep beams with heights of about $1000 \mathrm{~mm}$, including load-displacement relationships, crack propagation, and the effect of shear reinforcing steel, which indicates that it can be utilized to investigate the mechanism of the size effect on the shear strength of RC deep beams of similar scale.

\section{Simulation of the size effect on the shear strength of RC deep beams}

Based on the design of the specimens involved in the previous section, the authors designed a group of beam models, and carried out a shear load numerical analysis, aiming to evaluate the size effect on the shear strength and the effect of shear reinforcing steel. Although the size effect on the shear strength of deep beams without stirrups was confirmed by several experimental and numerical studies (An et al. 1997; Walraven and Lehwalter 1994; Kosa et al. 2009; Tan et al. 2005), the mechanism of the size effect is still not clear, and this is the main target of this study, which will be discussed in the following sections.

\subsection{Numerical models overview}

Eighteen beam models were designed for the parametric study, as shown in Fig. 9. They have similar geometrical sizes to the specimens tested by Kosa et al. (2009), discussed in Section 3. For each beam, the shear span to depth ratio is 1.5 , and two layers of tensile steel bars are placed within a concrete cover thickness of $50 \mathrm{~mm}$ (tensile steel ratio: $\rho_{t}=1.99 \%$ ). Beam models are divided into three groups, described by different stirrup ratios: $\rho_{w}=0.0 \%, 0.2 \%$ and $0.4 \%$, respectively. Within each group, only one variation is introduced, that is the beam effective depth $(d)$, that amount to $400,600,800,1000$, 1200 and $1500 \mathrm{~mm}$. The maximum stirrup ratio of $0.4 \%$

$0.1 \mathrm{~mm} 2.0 \mathrm{~mm}$
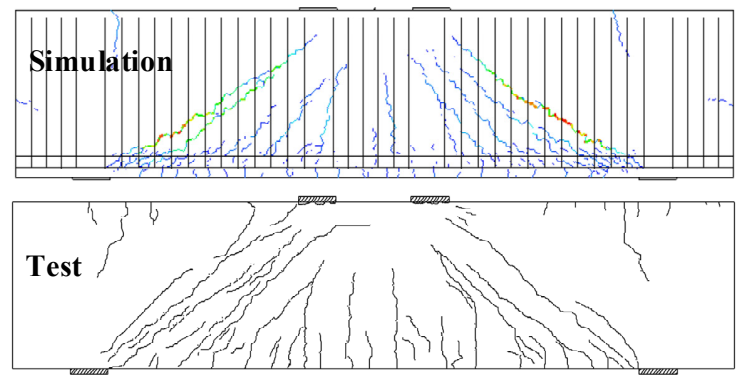

(b) Stirrups ratio $\rho_{w}=0.4 \%$

Fig. 8 Comparison of crack patterns between the simulation and experiment (experimental results refer to Kosa et al. 2009). 
is the same as that of the specimens tested by Kosa et al. (2009), while the maximum effective depth of beams in the numerical analysis is slightly larger. Other variations, i.e., the total cross sectional area of tensile steel bars, shear span length, range of pure bending region and loading and support plate lengths, are proportionally changed with the beam effective depth so that all the considered beams are geometrically similar. However, the widths of all beam models are intentionally kept constant at $280 \mathrm{~mm}$, although the widths of beams in Kosa et al. (2009)'s test are proportionally changed with beam heights. The authors consider to adopt the beam effective depth as the unique parameter for the design of the size effect, in order to match the current design codes (Standard Specifications for Concrete-Design (JSCE 2017), Eurocode 2 (CEN 2014), GB 50010-2010 (MOHURD 2015)), where a beam effective depth is generally recognized as a main variable in the formulas for size effect. As another advantage, the constant beam width can significantly reduce the calculation consumption and save the calculation time.
When it comes to beams with stirrups, five sets of closed stirrups are placed in the target shear span (the span at the right side in Fig. 9b), with the spacing of $d / 4$. The stirrups amount is changed by changing the cross sectional area of stirrup bars $\left(A_{s 2}\right)$. Compared with the target shear span, the shear spans at the left side are reinforced by "stronger" stirrups (cross sectional area $A_{s}$ $=3 A_{s 2}$ ), so that the shear failures occur at the target spans. This setting method makes it easier to observe and compare the crack occurrence and development.

The above designed specimens were modeled by using the 3D RBSM, according to the method discussed in Section 3. Also, $30 \mathrm{~mm}$ concrete elements in the average mesh size were adopted for all specimens. The examples of mesh design for the beam models with and without stirrups are illustrated in Fig. 10. In addition, Table 2 gives the critical material properties for steel bars and concrete which were used in the simulation.

\subsection{Numerical results}

It is firstly observed that all the beams suffer from shear

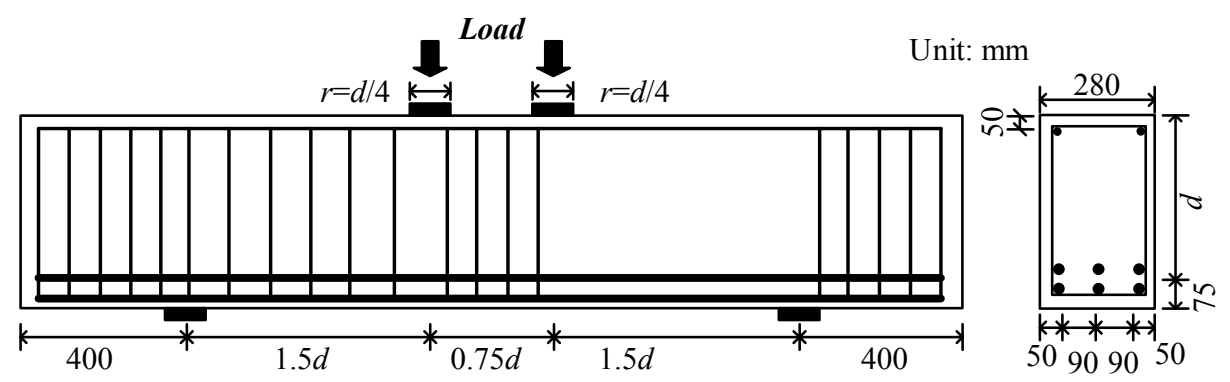

(a) Beam without stirrups $\left(\rho_{w}=0.0 \%\right)$

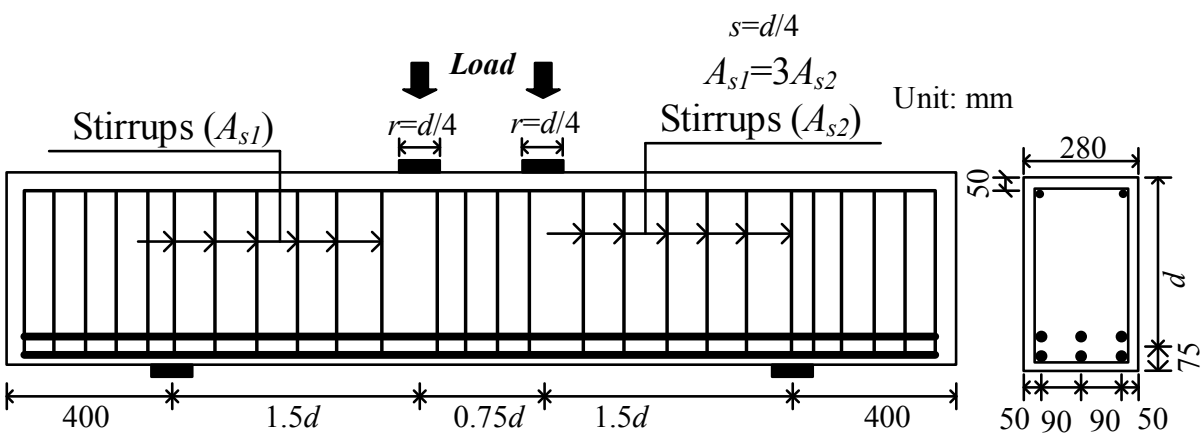

(b) Beam with stirrups $\left(\rho_{w}=0.2 \%, 0.4 \%\right)$

Fig. 9 Design drawings of RC deep beams for parametric study.

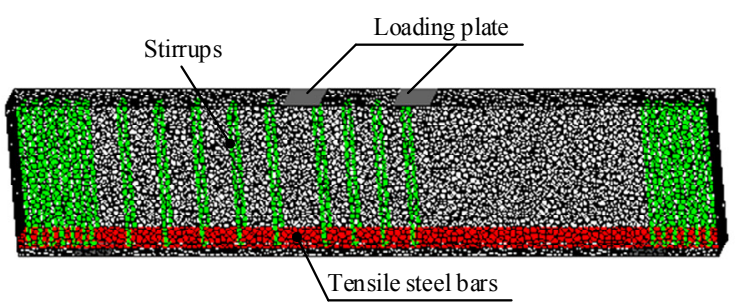

(a) Specimen without stirrups in failure $\operatorname{span}\left(\rho_{w}=0.0 \%\right)$

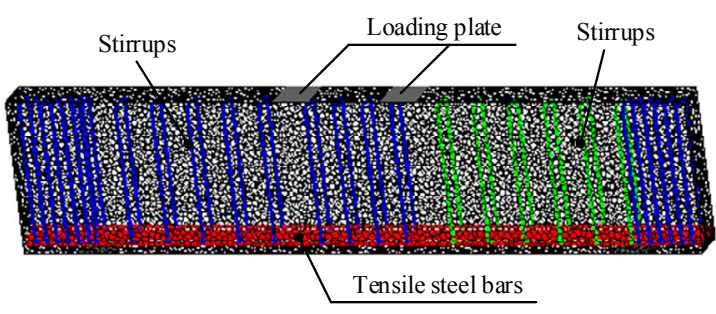

(b) Specimen with stirrups in failure span $\left(\rho_{w}=0.2 \%, 0.4 \%\right)$

Fig. 10 Illustration of the beam models. 
Table 2 Material properties used in numerical models.

\begin{tabular}{|c|c|c|c|c|}
\hline Tensile reinforcement & Stirrups & \multicolumn{3}{|c|}{ Concrete } \\
\hline Yield stress & Yield stress & Compressive strength & Tensile strength & Fracture energy \\
$f_{s y}(\mathrm{MPa})$ & $f_{w y}(\mathrm{MPa})$ & $f_{c}(\mathrm{MPa})$ & $f_{t}(\mathrm{MPa})$ & 2.23 \\
\hline 500 & 295 & 30 & $\mathrm{~N} / \mathrm{m})$ \\
\hline
\end{tabular}

compression failure and present similar deformation and cracking behaviors to those of the beams described in Section 3.3. Numerically obtained shear stress-displacement relationships for each beam are provided in Fig. 11, where the results are classified into three groups with different stirrup ratios. The shear stress (vertical axis) refers to the ratio of an external shear force to the effective beam cross section area $(b d)$. Additionally, the circular marks in Fig. 11a represent the shear stresses when the diagonal cracks initiate. Consequently, for each beam group, the shear crack stress and the normalized shear strength generally decrease with the increase in beam effective depth, which indicates a size dependence, regardless of the stirrup usage. But, the reduction rate of the shear cracking stress is higher than that of the normalized shear strength. In other words, the size effect on the shear strength is smaller than that on the shear cracking load. Moreover, it is noted that in the situations where the beam effective depth exceeds $1000 \mathrm{~mm}$, the reduction rate of the normalized shear strength gradually decreases, and in some isolated cases, the relatively deeper beams even exhibit a little higher normalized shear strengths (Fig. 11b). For example, the normalized shear strength of the beam " $\rho_{w}=0.2 \%, d=1200 \mathrm{~mm}$ " is slightly higher than that of the beam " $\rho_{w}=0.2 \%, d=$ 1000 mm" (Fig. 11b). The reason may be the fact that the shear strength of a deep beam depends on the crack propagation at the compression strut, thereby if the diagonal crack tips expand to the concrete beneath a loading plate, the failure may be delayed and the peak load may rise further, even if the beam height is relatively larger. Furthermore, the geometries of concrete particles are randomly produced due to the characteristics of the 3D RBSM, and due to the random mesh design, the crack propagation or crack path may show a little difference, which leads to a little larger peak load for a relatively higher beam, although the crack pattern and shear failure mode are not affected and remain unchanged.

The relationship between normalized shear strength and beam effective depth is presented in Fig. 12. The changes of the normalized shear strength show similar trends regardless of the stirrups presence, although the shear strength at the same depth is slightly enhanced. The normalized shear strength gradually decreases with the increase in the beam effective depth, and the deterioration rate becomes a little smaller though the deterioration trend continues when the beam effective depth exceeds $1000 \mathrm{~mm}$. Specifically, for the beam group without stirrup, $\rho_{w}=0.0 \%$, the deterioration rate of normalized shear strength is $11.1 \%$ and $7.8 \%$, respectively, when the beam effective depth increased from $400 \mathrm{~mm}$ to $1000 \mathrm{~mm}$ and from $1000 \mathrm{~mm}$ to $1500 \mathrm{~mm}$; for the beam group with stirrup, $\rho_{w}=0.2 \%$, the deterioration rate is $17.4 \%$ and $1.5 \%$, respectively; for the beam group with stirrup, $\rho_{w}=0.4 \%$, the deterioration

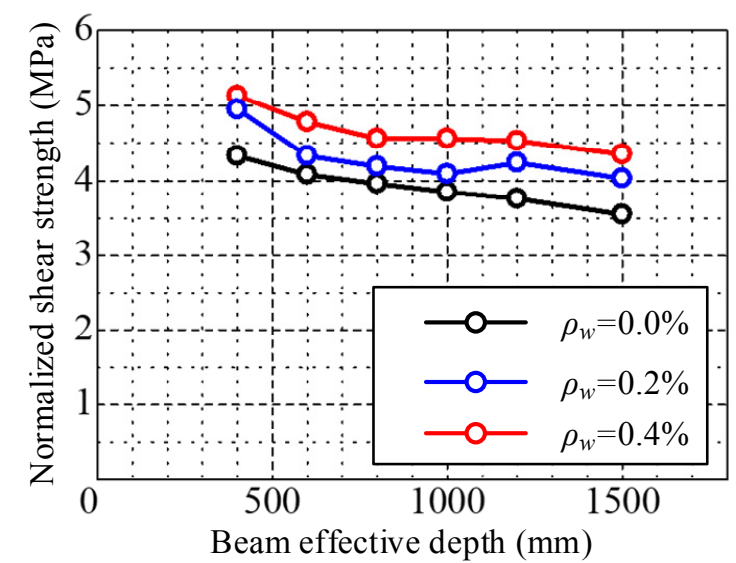

Fig. 12 Relation between normalized shear strength and beam effective depth.

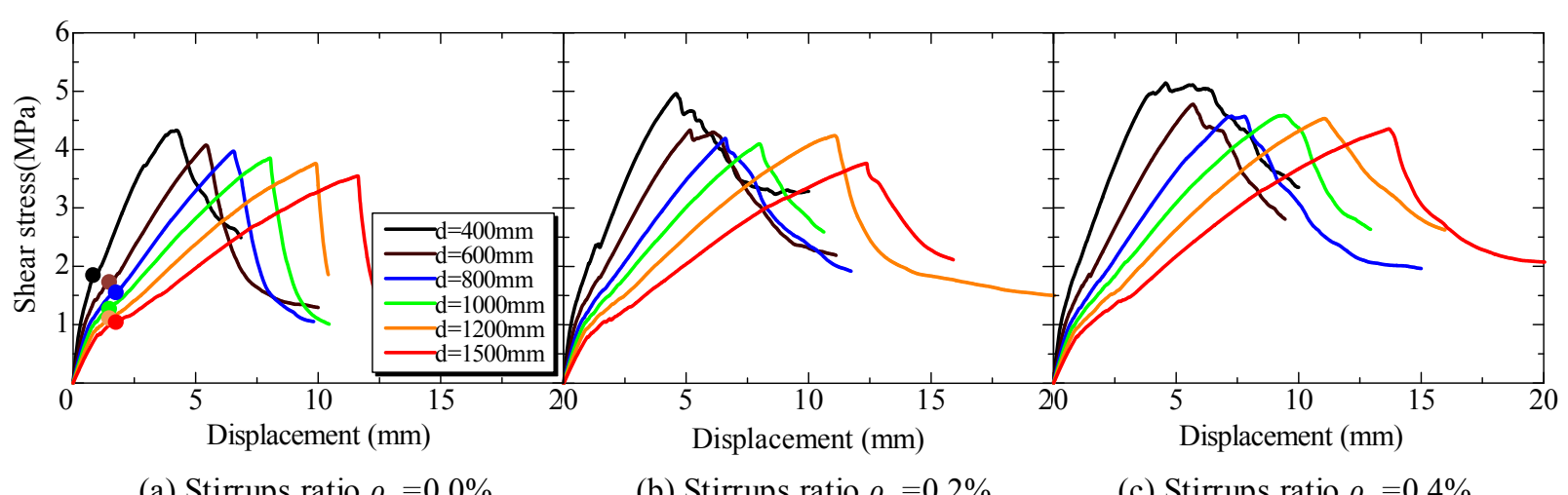

(a) Stirrups ratio $\rho_{w}=0.0 \%$

(b) Stirrups ratio $\rho_{w}=0.2 \%$

(c) Stirrups ratio $\rho_{w}=0.4 \%$

Fig. 11 Shear stress-displacement relationships. 
rate is $11.1 \%$ and $4.6 \%$, respectively. The same kind of behavior is also confirmed experimentally and numerically by Walraven and Lehwalter (1994) and An et al. (1997).

\section{Discussion of the size effect mechanism on the shear strength of RC deep beams}

\subsection{Contributions of shear resistance compo- nents to the size effect}

\subsubsection{Decoupling method for shear resistance} components

It is a fundamental theory that the basic shear resistance components of an RC member consist of beam and arch actions. The decoupling method for beam and arch actions by using the numerical results of the 3D RBSM was applied and demonstrated by $\mathrm{Fu}$ et al. (2017a, 2017b, 2020) and Nakamura et al. (2018). This section describes the basic concepts of the decoupling method.

For an RC beam, beam and arch actions can be derived from the mechanical equilibrium in an arbitrary cross section, according to Eq. 1 (Fig. 13). By differentiating Eq. 1, Eq. 2 which represents the shear resistance effects can be obtained, and it can be divided into two components, described with Eqs. 3 and 4,

$$
\begin{aligned}
& M=\left(T_{s}+C_{s}\right) \cdot \frac{j_{s}}{2}+C_{c} \cdot j_{C c}+T_{c} \cdot j_{T c} \\
& V=\frac{d M}{d x}=V_{b}+V_{a} \\
& V_{b}=\left(\frac{d T_{s}}{d x}+\frac{d C_{s}}{d x}\right) \cdot \frac{j_{s}}{2}+\frac{d C_{c}}{d x} \cdot j_{C c}+\frac{d T_{c}}{d x} \cdot j_{T c} \\
& V_{a}=C_{c} \cdot \frac{d j_{C c}}{d x}+T_{c} \cdot \frac{d j_{T c}}{d x}
\end{aligned}
$$

where $M$ is the bending moment in a cross section; $V$ is the combined shear resistance; $V_{b}$ is the shear resistance provided by the beam action; $V_{a}$ is the shear resistance provided by the arch action; $T_{s}$ and $C_{s}$ are the internal forces sustained by tensile and compressive steel bars; $T_{c}$ and $C_{c}$ are the concrete tensile and compressive resultants; $j_{s}$ is the lever arm between the centroids of tensile and compressive steel bars; $j_{T c}$ and $j_{C c}$ are the lever arms between the centroids of concrete tensile and compressive resultants and the beam axis; $d x$ is the in-

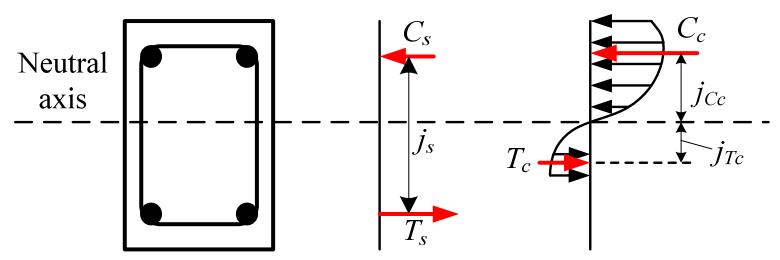

$\begin{array}{lll}\text { (a) Cross section of } & \text { (b) Stress in } & \text { (c) Section stress in }\end{array}$ RC member reinforcing bars concrete Fig. 13 Stress state in an arbitrary cross section of RC beam. tegral unit segment along the beam axis which in this study was chosen to be $50 \mathrm{~mm}$.

All necessary differential values of localized forces on the adjacent cross sections within the unit $d x$ involved in Eqs. 3 and 4 can be calculated by using numerical stress results from each concrete and steel bar element. Furthermore, beam and arch actions within $d x$ due to the change of localized forces can be calculated. It is known that the beam action is attributed to the change rate of forces in steel bars and concrete resultants along the beam axis, while the arch action is a consequence of the change rate of centroids of concrete compressive and tensile resultants along the beam axis.

Furthermore, as a component of the beam action, a truss action provided by stirrups can be estimated at each loading stage, based on the truss theory. It can be described with Eq. 5 (Standard Specifications for Concrete-Design (2017)), established on the basis of the hypothesis that the inclination of critical diagonal crack relative to member axis is $45^{\circ}$.

$$
V_{s}=\frac{A_{w} \cdot \sigma_{w} \cdot j d}{s}
$$

where $A_{w}$ is the total area of stirrups spaced at the distance $s ; \sigma_{w}$ is the maximum stress in one set of stirrups at the loading stage; $j d$ is the moment lever arm $(j=$ $1 / 1.15)$.

The average truss action of all sets of stirrups intersected by a critical diagonal crack is adopted to evaluate the level of the truss action at each loading stage. Moreover, the other component of the beam action, concrete contribution $V_{c}$ at each loading stage, can be obtained by removing the average truss action from the average beam action. The total concrete contribution $V_{c o n}$ to shear strength, as an important shear resistance component specified in current design codes [Standard Specifications for Concrete-Design (JSCE 2017), ACI 318M-14 (ACI 2015), fib Model Code 2010 (fib 2013) and GB 50010-2010 (MOHURD 2015)], is consistent with the combined effect of the arch action and concrete contribution $V_{c}$ for the beam action.

\subsubsection{Examples of decoupling results}

The decoupling result for a typical specimen where the main structural factors are " $\rho_{w}=0.4 \%, d=1500 \mathrm{~mm}$ ", is described in detail to comprehend the development of each shear resistance component expressed as a normalized shear stress (Fig. 14). Black curves represent the load responses simulated by the 3D RBSM, and the beam deformations corresponding to the load stages marked by (1) to (4) were magnified by five times for clearer observation. The reasonability of the decoupling method can be understood from the fact that the combined effect of beam and arch actions (green curve) is in a good agreement with the external load obtained from the simulation.

With regard to the growth of each shear resistance component, the beam action initially provides the shear 
resistance before the appearance of diagonal cracks. However, after diagonal cracking, the beam action remains stable, because the enhancement by stirrups (truss action $V_{s}$ ) rapidly rises and offsets the drop of concrete contribution $\left(V_{c}\right)$. Meanwhile, the arch action arises and drastically increases until the occurrence of the maximum load, and dominates the shear strength. The total concrete contribution $V_{c o n}$ is mainly provided by $V_{c}$ before diagonal cracking and the arch action after diagonal cracking, respectively. Ultimately, due to the compression failure of the concrete compression strut in the vicinity of tensile steel bars and loading plate, the arch action and total load steeply drop. Obviously, the decoupling clarifies the dominant shear resistance component at each loading stage and the specific contributions of concrete and stirrups, together with the development of cracks. It is recognized that this kind of approach is very effective to evaluate the shear resistance components of RC members (Nakamura et al. 2018; Yamada 2019; Gunawan et al. 2020; Fu et al. 2020).

\subsubsection{Size effect on each shear resistance com- ponent}

Besides the typical beam model " $\rho_{w}=0.4 \%, d=1500$ mm" described in Section 5.1.2, the shear resistance components (the arch, beam and truss actions, and concrete contribution to the beam action $V_{c}$ ) were also decoupled for other specimens. The corresponding results at the maximum loading stages are shown in Fig. 15 in the form of shear stress-beam effective depth relationships. For the beam group without stirrups, the arch action carries the majority of shear resistance compared to the other shear contributions, and the clear size effect on the arch action can be observed (Fig. 15a). But for beams with effective depths larger than $1000 \mathrm{~mm}$, the size effect becomes very small. In contrast, the beam action only contributes approximately $10 \%$ to the normalized shear strength, and its size dependence is negligible (Fig. 15b).
For beam groups with stirrups, the arch action is similar to the beams without stirrups, and also the similar size effect can be observed, independent on the level of stirrup ratio (Fig. 15a). In opposite, the beam action is enhanced by the stirrups, and the greater the stirrup ratio, the higher the beam action (Fig. 15b). However, their grades are almost independent on the beam effective depth. The grades of truss action only depend on the stirrup amount, i.e., a proportional relation to the stirrup ratio can be observed because the stirrups in each beam yield at the maximum loading stage (Fig. 15c). The concrete contributions $V_{c}$ for the beam action are very small at the maximum loading stages, compared to the arch and truss actions, and they slightly decrease with the stirrup ratio increase (Fig. 15d). In addition, it is noted that the concrete contributions $V_{c}$ for some of the beams at stirrup ratio of $0.4 \%$ present negative values. This is because the truss action $V_{s}$ of these beams were overestimated that the assumed value, $45^{\circ}$ of diagonal crack angle, is probably different from actual diagonal crack angle.

To summarize, it is clear from the presented results that the size dependence in the shear strength of RC deep beams mainly depends on the arch action, and it is worth noting that the size effect on the arch action is significant if the beam effective depth is smaller than $1000 \mathrm{~mm}$. For beams with larger depths, the descending trend of the normalized arch action due to the size increase becomes flattening out. Specifically, for the beam group without stirrup, $\rho_{w}=0.0 \%$, the deterioration rate of normalized arch action is $10.5 \%$ and $6.3 \%$, respectively, when the beam effective depth increases from $400 \mathrm{~mm}$ to $1000 \mathrm{~mm}$ and from $1000 \mathrm{~mm}$ to $1500 \mathrm{~mm}$; for the beam group with stirrup, $\rho_{w}=0.2 \%$, the deterioration rate is $20.2 \%$ and $-1.8 \%$ (negative percentage means a minor increase), respectively; for the beam group with stirrup, $\rho_{w}=0.4 \%$, the deterioration rate is $9.4 \%$ and $3.1 \%$, respectively.
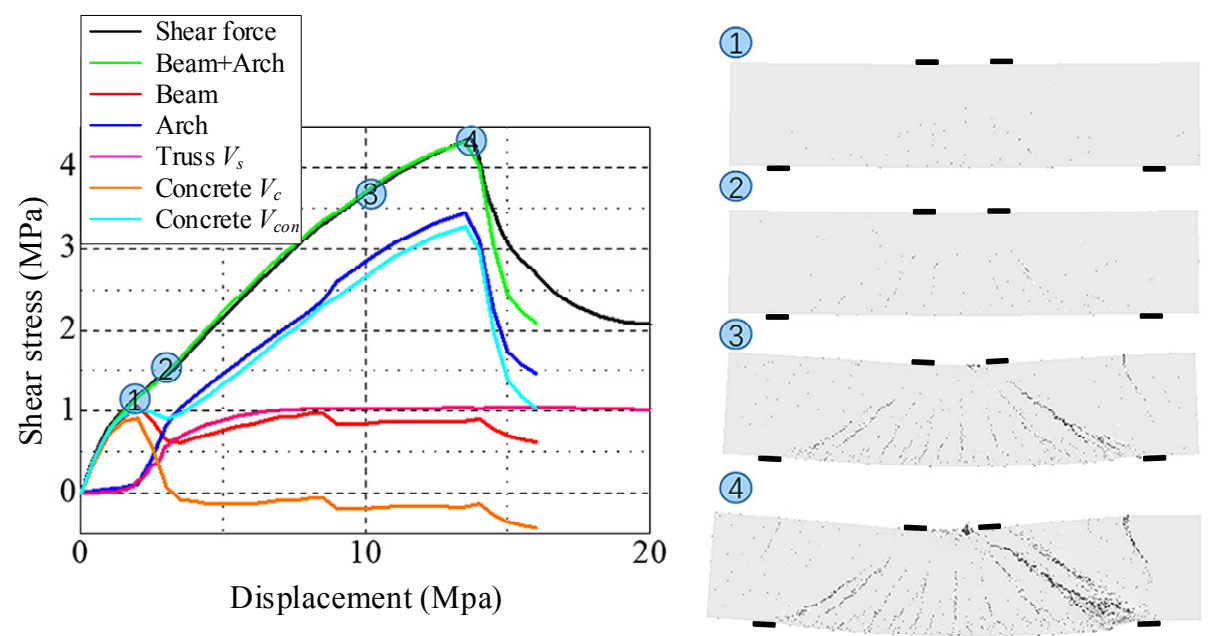

Beam with stirrups $\left(\rho_{w}=0.4 \%, d=1500 \mathrm{~mm}\right)$

Fig. 14 Examples of decoupling result for shear resistance components. 


\subsection{Mechanism of the size effect on the arch action of RC deep beams}

According to the analytical results discussed in Section 5.1 , it becomes clear that the size effect on the shear strength of RC deep beams is mainly caused by the size effect on the arch action, which is not affected by stirrups. This section will focus on the mechanism of the descending trend of the arch action due to the beam effective depth increase.

\subsubsection{Critical factor for the size effect on the arch action}

According to Eq. 4, the calculation for the arch action consists of two components: $C_{c} \cdot d j_{C c} / d x$ and $T_{c} \cdot d j_{T_{c}} / d x$, which are the functions of concrete compressive and tensile resultants and the lever arms between the centroids of concrete resultants and the beam neutral axis. Since concrete tensile resultant, $T_{c}$, is extremely small and usually ignored in structural design, the authors will only focus on the analysis of two items, $C_{c}$ and $d j_{C d} / d x$, aiming to find out the critical factor for the size dependence of the arch action.

Above all, the distribution of the arch action, $V_{a}$, along the beam axis within $50 \mathrm{~mm}$ space at the maximum loading stage, is firstly shown in Fig. 16 for two beam groups: $\rho_{w}=0.0$ and $0.4 \%$. The horizontal axis represents the location of each integral unit $d x$ along the beam axis normalized as $x / a$ ( $x$ : the distance of an integral unit from the loading point, $a$ : shear span length), and the vertical axis represents the value of arch action

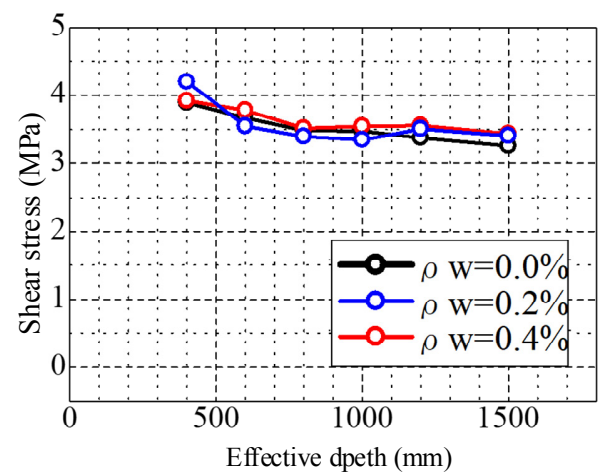

(a) Arch action

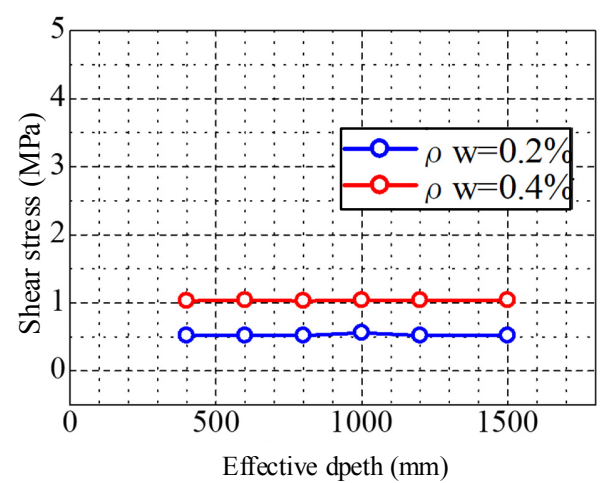

(c) Truss action

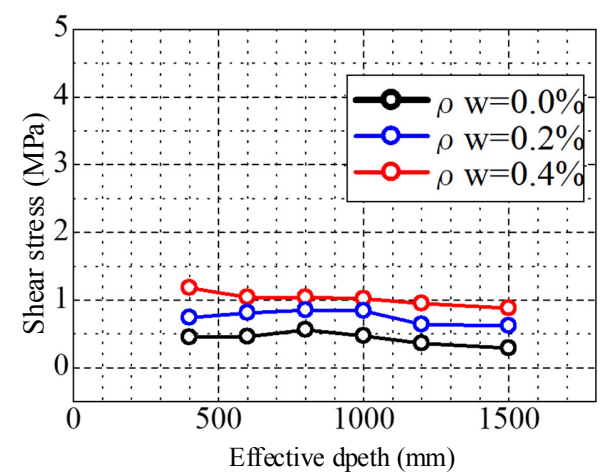

(b) Beam action

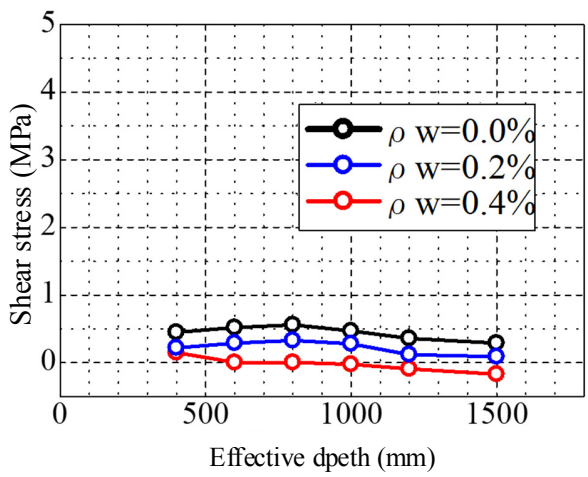

(d) Concrete contribution for beam action $\left(V_{c}\right)$

Fig. 15 Size effect on each shear resistance component.

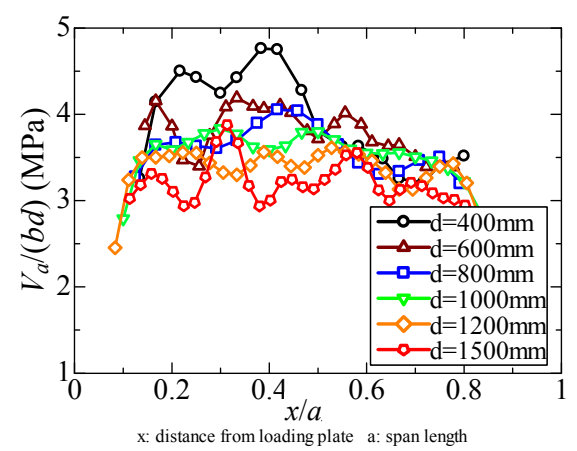

(a) Stirrups ratio $\rho_{w}=0.0 \%$

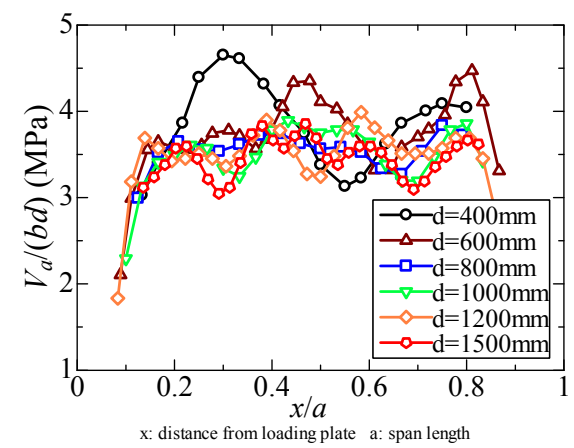

(b) Stirrups ratio $\rho_{w}=0.4 \%$

Fig. 16 Distribution of the nominalized arch action $V_{a} /(b d)$. 
normalized as $V_{a} /(b d)$. The distributions show an irregular variation along axial direction, because the local stress values are sensitive to formation of cracks. However, even considering the variation, it is still noticeable that the overall grade of $V_{a} /(b d)$ along beam axis decreases with the increase in the beam effective depth for the two beam groups indicating the size dependence. Although the presence of stirrups slightly improves the overall grade of arch action, it cannot eliminate the size effect.

As one critical factor for arch action, the distribution of the concrete compressive resultant, $C_{c}$, along the beam axis is plotted in Fig. 17 for the two beam groups. The vertical axis represents the concrete compressive resultant normalized as $C_{c} /(b d)$. Consequently, for each specimen, a descending trend can be seen in the distribution of concrete compressive resultant from the loading plate side $(x / a=0)$ to the support side $(x / a=1)$, and the overall distribution of concrete compressive resultant is enhanced by stirrups. Furthermore, it can be seen that the overall grade of $C_{c} /(b d)$ along the beam axis decreases with the increase in the beam effective depth, indicating an evident size dependence regardless of the use of stirrups.

Moreover, the arch action calculated by Eq. 4 includes the effect of the differential value of lever arm $\left(j_{C c} d d x\right)$ related to centroid of concrete compressive resultant. Aiming to investigate the size dependence of $d j_{C c} d d x$, the axial distribution of lever arm $j_{C c}$ at the maximum loading stage for the two beam groups are shown in Fig. 18. The vertical axis represents the lever arm of the concrete compressive resultant normalized as $j_{C d} d d$, and the negative values mean that the centroid of the resultant is below the beam axis. For each beam group, $j_{C d} / d$ of all specimens is almost linearly distributed along the beam axis, and the slopes of the distribution curves $\left(d j_{C d} / d x\right)$ almost show same value, which is not affected by the change of the effective depth and stirrup ratio.

Thus, according to the above results, it can be concluded that the crucial factor for the size effect on the arch action is the size dependence of the overall grade of the concrete compressive resultant $C_{c}$.

\subsubsection{Size dependence mechanism of the arch action}

Since it was shown that the size effect on the arch action is mainly caused by the concrete compressive resultant $C_{c}$, in this section the change of the concrete compressive stresses in beam cross sections due to the variation of beam effective depths and stirrup ratio is evaluated.

Figure 19 shows crack patterns, the distribution of compressive stress in the axial direction (both in the longitudinal central section) and the comparison of compressive stress in typical cross sections for the two beams without stirrups and with different depths: $d=$ 400 and $1500 \mathrm{~mm}$. The presented results correspond to the maximum loading stage. Both beams show similar shear failure modes, i.e., the significant propagation of critical diagonal cracks cause the shear compression

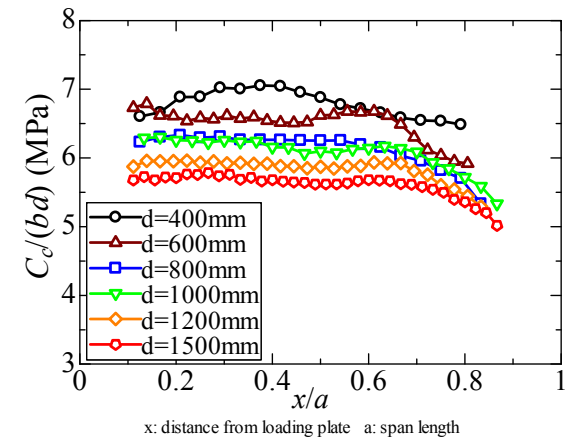

(a) Stirrups ratio $\rho_{w}=0.0 \%$

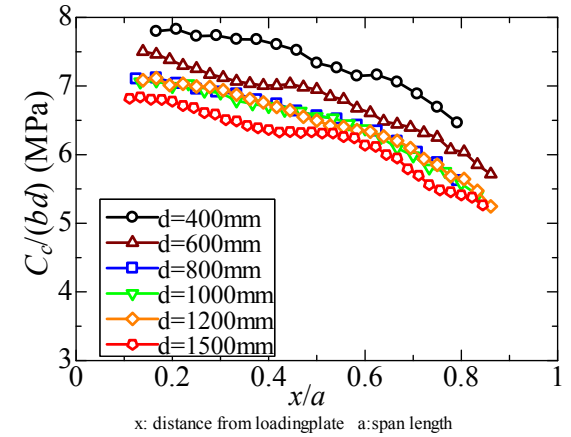

(b) Stirrups ratio $\rho_{w}=0.4 \%$

Fig. 17 Distribution of the nominalized concrete compressive resultant $C_{c} /(b d)$.

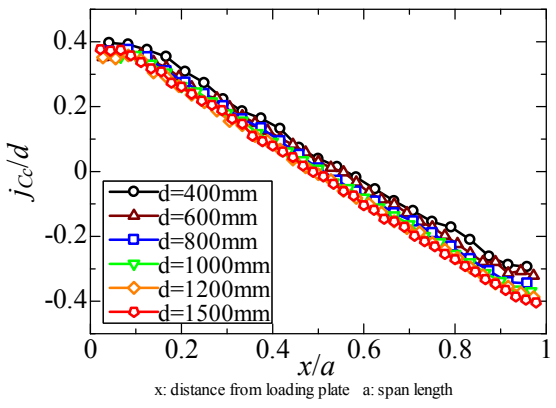

(a) Stirrup ratio $\rho_{w}=0.0 \%$

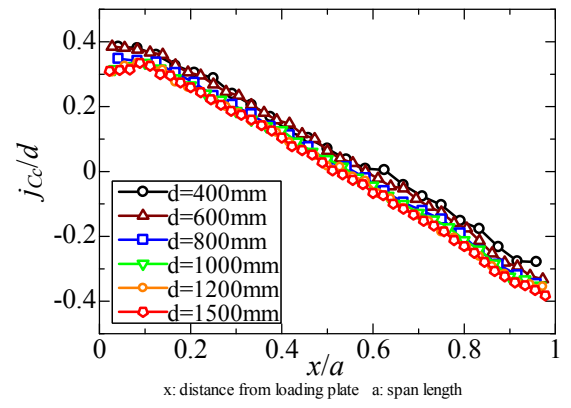

(b) Stirrup ratio $\rho_{w}=0.4 \%$

Fig. 18 Distribution of the nominalized arm length $j_{c d} / d$. 
failure in the target (right) span (Fig. 19a). However, the diagonal crack in the larger beam is more localized and wider, which is consistent with the findings from the previous studies (Walraven and Lehwalter 1994; Kosa et al. 2009; Zhang and Tan 2007). The rough crack width can be known from the different color of cracks in the figure legend, and the red color refers to the crack with a width no smaller than $3.0 \mathrm{~mm}$. The result confirms that the 3D RBSM has the advantage of reasonably reproducing dispersed cracks, and quantitatively evaluating localized stress, which is practical and an effective way to evaluate the mechanism of size effect on the shear performance. From Fig. 19b, it can be observed that the stocky compression struts wrapping the diagonal cracks are generated for both beams, but the stress grade in the central zone of the compression strut in the larger beam is evidently smaller, which is known from the different colors of stress by referring to the figure legend (stress with red color is greater than $20 \mathrm{MPa}$ ). Thus, it is considered that the significant reduction of the compressive stress in the larger beam causes the degradation of the compressive resultant $C_{c}$, which is related with the degradation of the arch action. The detailed difference in compressive stresses acting on the cross sections located nearby the loading point, central section in shear span and the support point $(x / a=0.2$, $0.5,0.7)$, marked by red straight lines in Fig. 19b, are
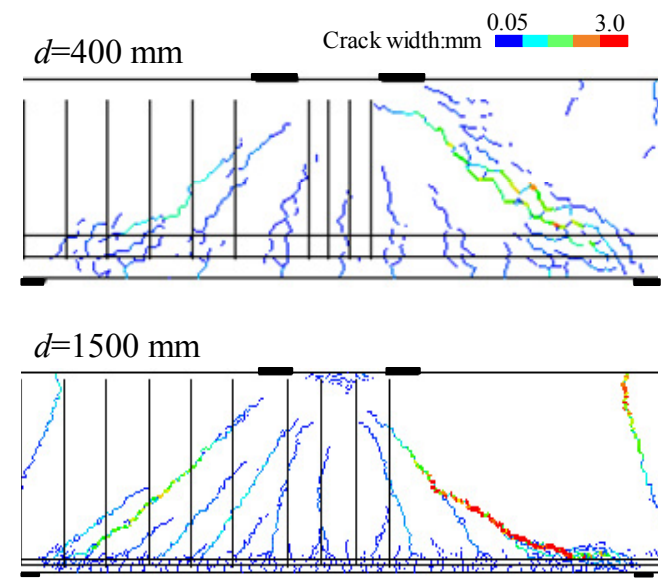

(a) crack pattern in longitudinal central section
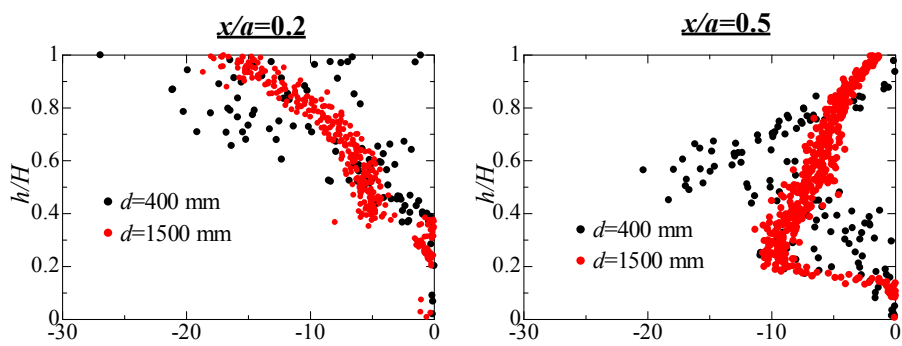

(c) Compressive stress in beam cross sections

Fig. 19 Localized information for beams without stirrups $\left(\rho_{w}=0.0 \%\right)$. $x$ and a are the distance to the center of loading plate and shear span length, respectively. $h$ and $H$ are the position of concrete element in vertical direction and the total height of beam, respectively. Negative value in horizontal axis represents compressive stress state.

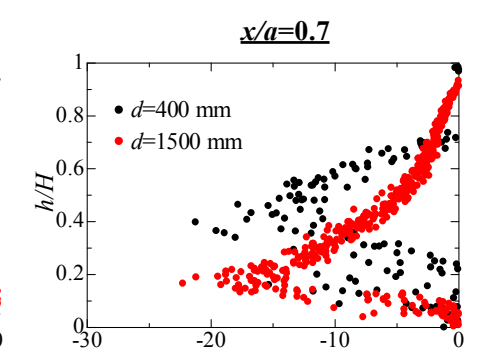

given in Fig. 19c. The results show that the compressive stresses on the cross sections overall decrease, in particular on the section nearby loading point which is close to the crushing failure zone of concrete and the central cross section in shear span which belongs to the major diagonal crack zone.

It is assumed that the reason for the size dependence of the compressive stress in the axial direction or the concrete compressive resultant $C_{c}$ at the maximum loading stage is related to the increasing trend of the diagonal crack width with the beam size. As mentioned in the previous section, the relative displacement between each two adjacent concrete particles at each loading stage can be estimated and it is regarded as the localized crack width at the location of the concrete particles. On the basis of this method, the maximum crack widths at the typical cross sections (at the maxition along failure shear span for the beam group without stirrups $(d=400,1000,1500 \mathrm{~mm})$ is outlined in Fig. 20a. It is seen that the distribution of crack width varies along shear span and the maximum value is located at the central zone of shear span. More importantly, the crack width increases significantly along the entire span with beam effective depth. That is, on the sections located nearby loading point $(x / a<0.2)$, i.e., crushing failure zone of concrete, the crack width ranges from

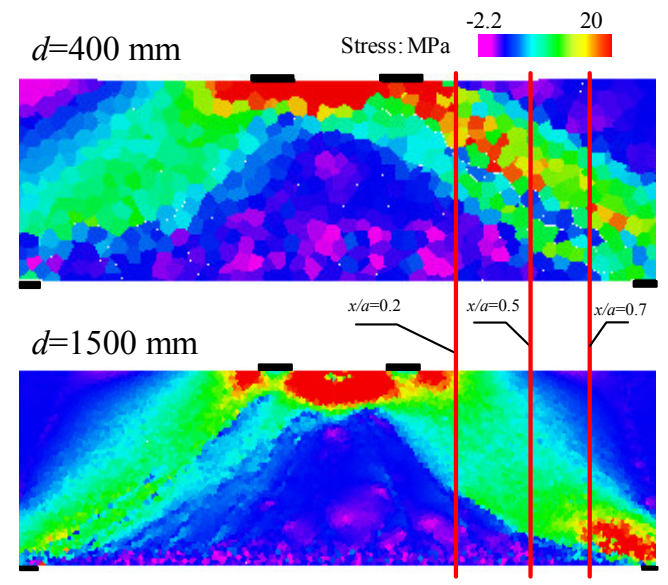

(b) Compressive stress in longitudinal central section 
0.65 to $1.53 \mathrm{~mm}$ for the smallest beam $(d=400 \mathrm{~mm})$, from 1.45 to $2.57 \mathrm{~mm}$ for the beam with $d=1000 \mathrm{~mm}$ and from 1.99 to $4.05 \mathrm{~mm}$ for the largest beam $(d=$ $1500 \mathrm{~mm}$ ). Further, the growth of the maximum value of the axial distribution is plotted in Fig. 20b. It is clear that the crack widths show similar widening speed regardless of the beam size change, and that the crack width at the maximum loading stage becomes bigger with the beam size increase.

In terms of the relation between crack width and the compressive strength of concrete, Collins et al. (1983), Miyahara et al. (1987) and Cervenka et al. (2014) confirmed that the concrete compressive strength decreases when the distributed cracks parallel to the loading direction. Nakamura et al. (2018) investigated the influence of a single axially distributed crack on the compressive strength of concrete by the compression test on cylinder or prism specimens, and found that the biggest compressive strength drop reaches approximately $30 \%$, and if the crack width exceeds an upper value, no further deterioration occurs. Recently, also via compression tests on prism specimens, Miura et al. (2020) introduced one single crack with a certain angle to the loading direction and confirmed the relationship between crack angle and width and concrete compressive strength. As a typical result, in the case of specimens with a crack parallel to loading direction, the biggest compressive strength drop reaches approximately $30 \%$ as crack width increases from 0 to $1.5 \mathrm{~mm}$, and if the crack width exceeds the upper value, around $1.5 \mathrm{~mm}$, no significant deterioration occurs. In addition, in the case of the specimen with an initial crack 30 degree to loading direction, the concrete compressive strength decreases by nearly $70 \%$ when the crack width reaches $1.0 \mathrm{~mm}$.

In the compression strut of a deep beam, a number of diagonal cracks parallel or having an angle to the direction of the principal compressive stress will show at the failure stage, and this complex stress-crack condition is very similar to the experimental conditions designed by Nakamura et al. (2018) and Miura et al. (2020). There- fore, their findings can be incorporated with the stress condition of compression strut in RC deep beams, and it is deemed that the increase in the diagonal crack widths will lead to the reduction in the compressive strength of strut and also will have a certain influence on the reduction ratio under the condition of large crack width.

Similar to Fig. 19, Fig. 21 shows the crack patterns and the distributions of the compressive stress in the axial direction for the two beams with stirrups and different depths: $d=400$ and $1500 \mathrm{~mm}$. It can be observed that more diagonal cracks (Fig. 21a) are generated in the failure span in contrast to the beams without stirrups (Fig. 19a), but the critical diagonal crack pattern is not influenced by the stirrup presence. It is noticed that the critical diagonal crack width in the larger beam becomes bigger at the maximum load stage (Fig. 21a). Consequently, the compressive stresses in the strut of the larger beam shows an overall decrease, although the distributed area of compressive stress for the two beams is kept same (Figs. 21b and 21c).

The axial distribution of maximum crack width at the maximum load stage and the growth of the maximum crack width in failure shear span for the three typical beams with stirrups $(d=400,1000,1500 \mathrm{~mm})$ is plotted in Fig. 22. Similar to the results for the beams without stirrups, the distribution of crack width increasing with beam size increase shows a significant size effect (Fig. 22a). On the cross sections nearby loading point $(x / a<$ 0.2 ), the crack width varies from 0.46 to $0.90 \mathrm{~mm}$ for the smallest beam $(d=400 \mathrm{~mm})$, from 0.5 to $1.77 \mathrm{~mm}$ for the beam with $d=1000 \mathrm{~mm}$ and from 1.27 to 3.30 $\mathrm{mm}$ for the largest beam $(d=1500 \mathrm{~mm})$. As mentioned before, this phenomenon causes the gradual degradation of the concrete compressive strength in the strut and further the related arch action. Moreover, as plotted in Fig. 22b, the widening process of maximum crack with deflection increase is also confirmed, but due to the confining effect of stirrups, the crack opening widths at the same deflections are generally smaller (i.e., the slopes of curves are slightly lower) compared with those for

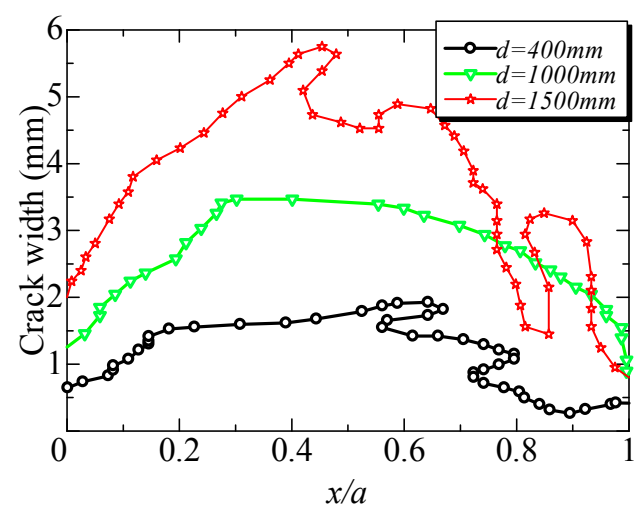

(a) Distribution of maximum crack width along beam axis at the maximum loading stage

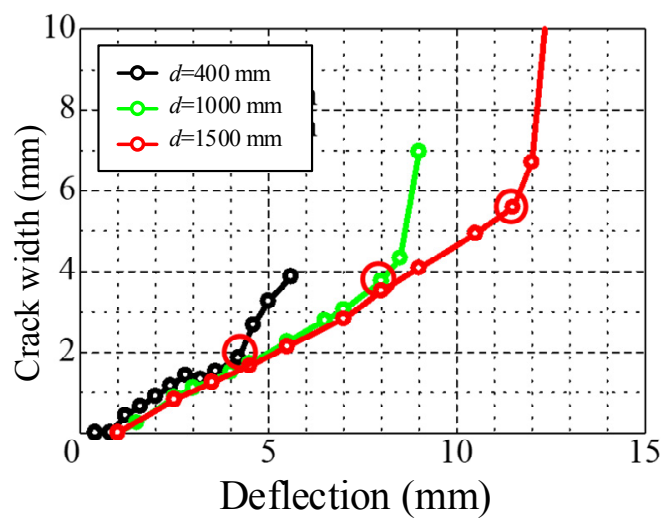

(b) Relation between maximum crack width and deflection

Fig. 20 Evaluation on crack width $\left(\rho_{w}=0.0 \%\right) . x$ and a are the distance to the center of loading plate and shear span length, respectively. Red circles in Fig. 20b mark the crack widths at the maximum loading stages. 
the beams without stirrups discussed above (Fig. 20b). To summarize, the use of stirrups cannot inhibit the increase in the diagonal crack width due to the beam effective depth increase, and this is the reason why the size dependence of the arch action is not eliminated by stirrups, which is consistent with the results shown in Fig. 15a.

With respect to the growth process of the maximum crack width shown in Figs. 20b and 22b, another interesting point is noted at the post-peak stage. For the beam group without stirrups, the diagonal crack widths increase more rapidly after the peak load, and the higher the beam, the sharper the increasing slope of curve (Fig. 20b). However, this size dependence of crack widening behavior at the post-peak stage cannot be observed in the beams with stirrups since no obvious turning points are seen at the maximum load stage in the growth curve of crack widths, regardless of the beam size change (Fig. 22b). This effect of stirrups on the cracking process at post-peak stage also reflects in variation of load-displacement curve. As shown in Fig. 11, in the cases of beams without stirrups, the larger the beam, the more dramatically the load drops at the post-peak stages, signifying a brittle failure behavior. In contrast, in the cases of beams with stirrups, the load drop slope is almost not affected by the beam size change. These re- sults indicate that different widening behavior of diagonal cracks due to the change of beam size and the presence of stirrups have an influence on the post-peak shear behavior of RC deep beams, besides on shear strength.

Kosa et al. (2009) reported that the normalized width of compression strut in the shear span of a RC deep beam is reduced if the beam effective depth increases, and this is a factor for the size effect in shear. However, their estimation on the range of compression strut is based on the distribution of strain measurement in compression strut rather than the stress result which is directly correlated with the shear resistance mechanism. In addition, their analytical result of crack propagation came from FEM tool which is prone to produce strain localization. Due to this, in this study, the size dependence of compression strut width was re-investigated based on the result of compressive stress distribution obtained from 3D RBSM taking an advantage of estimating crack propagation and zone. The relation between the width of compression strut at the maximum loading stage and the beam effective depth for the beam groups with and without stirrups $\left(\rho_{w}=0.0 \%\right.$ and $\left.0.4 \%\right)$ are compared in Fig. 23. The width of compression strut can be roughly determined based on the range of the distribution of compressive stress in the axial direction

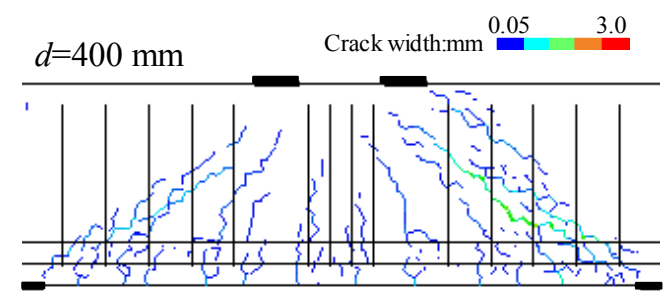

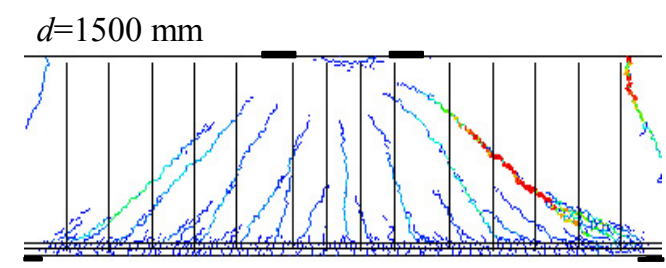

(a) crack pattern in longitudinal central section

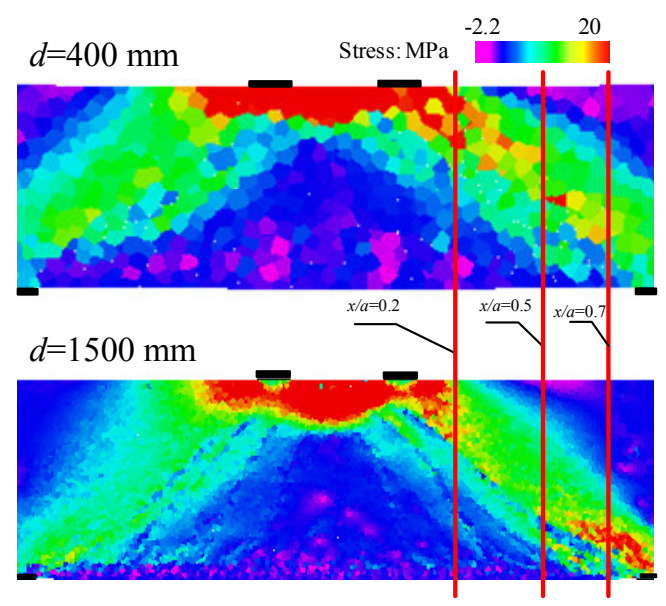

(b) Compressive stress in longitudinal central section
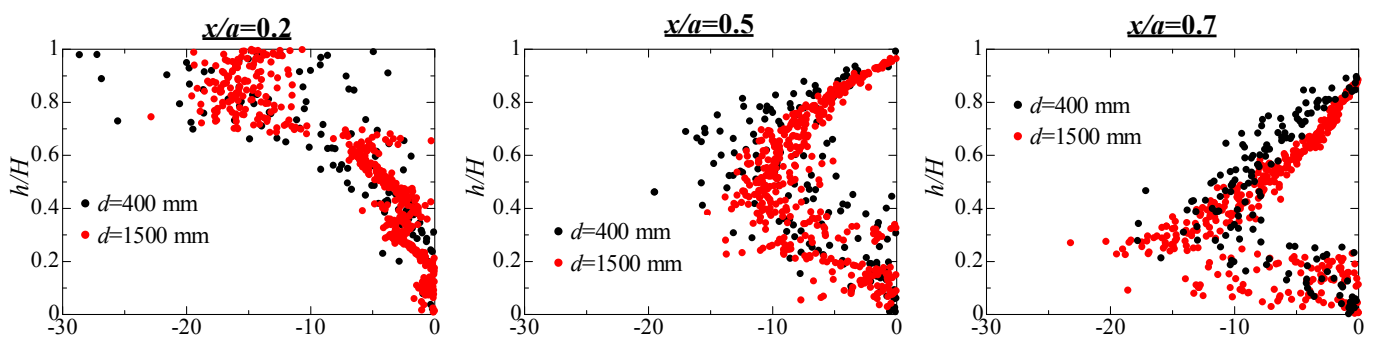

(c) Compressive stress in beam cross sections

Fig. 21 Localized information for beams with stirrups $\left(\rho_{w}=0.4 \%\right) . x$ and $a$ are the distance to the center of loading plate and shear span length, respectively. $h$ and $H$ are the position of concrete element in vertical direction and the total height of beam, respectively. Negative value in horizontal axis represents compressive stress state. 
(at the longitudinal central section) in the concrete struts (Fig. 23a). The strut widths $\left(w_{1}, w_{2}, w_{3}\right)$ at three positions nearby loading point, mid-height of strut and support point within shear span were separately estimated, and the relations between the normalized compression strut width $\left(w_{1} / d, w_{2} / d, w_{3} / d\right)$ and the beam effective depth are shown in Figs. 23b, c, d. It is confirmed that the decreasing trend of strut width with beam size increase is not significant at the positions nearby loading point $\left(x_{1} / a=0.2, x_{2} / a=0.5\right)$ dominating the compressive strength of strut concrete and the occurrence of shear failure. While the strut width nearby support point $\left(x_{3} / a=0.8\right)$ remarkably decreases, respectively, for the beam groups without and with stirrups when the beam effective depth increases from 400 to $1500 \mathrm{~mm}$. These results prove that the size dependence of compression strut width is probably one of the factors for size effect in shear, but since the size effect in strut width mainly occurs at the zone close to support point rather than the area of shear compression failure, it is thought not to be the dominant factor compared with the influence of the size effect in diagonal crack width, concrete compressive strength of strut concrete and arch action discussed above.

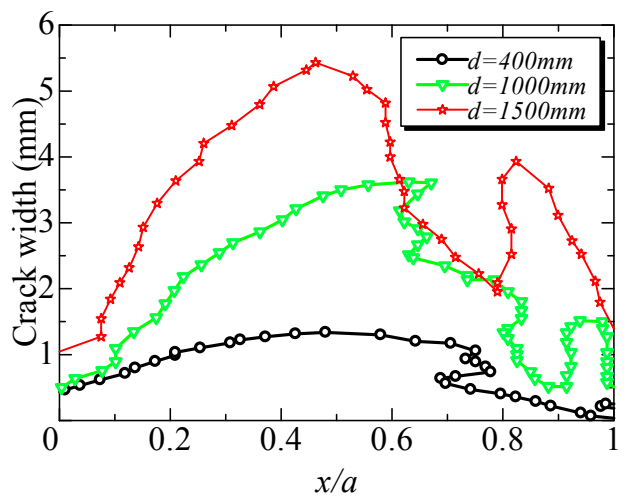

(a) Distribution of maximum crack width along beam axis at the maximum loading stage

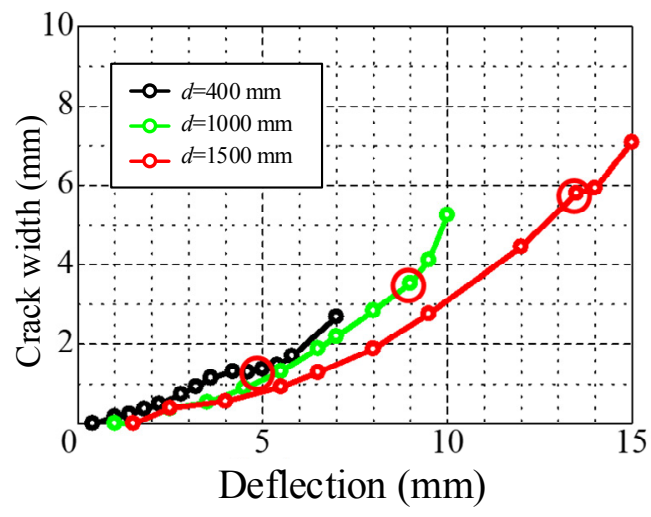

(b) Relation between maximum crack width and deflection

Fig. 22 Evaluation on crack width $\left(\rho_{w}=0.4 \%\right) . x$ and a are the distance to the center of loading plate and shear span length, respectively. Red circles in Fig. 22b mark the crack widths at the maximum loading stages.

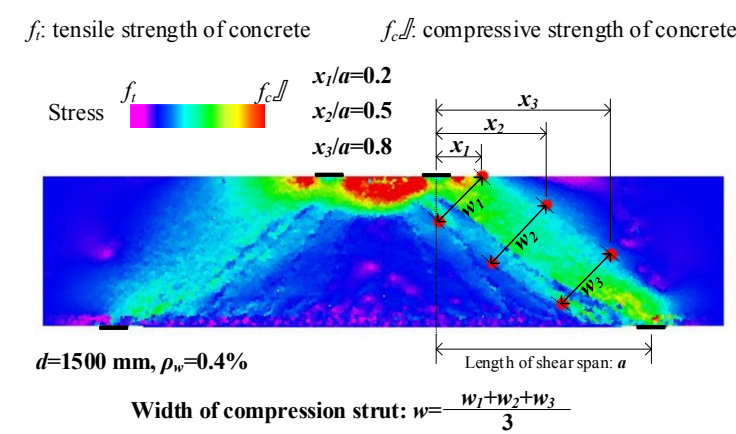

(a) Estimation method for width of compression strut $w$

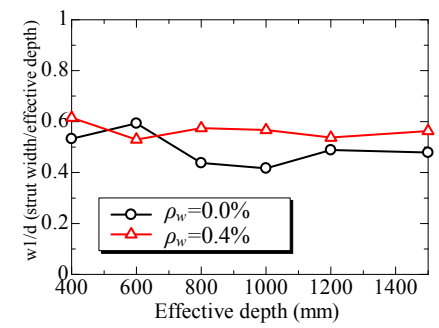

(b) Position: $x_{1} / a=0.2$

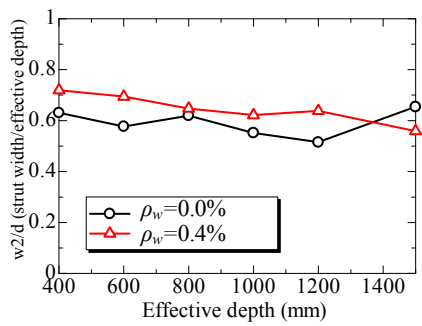

(c) Position: $x_{2} / a=0.5$

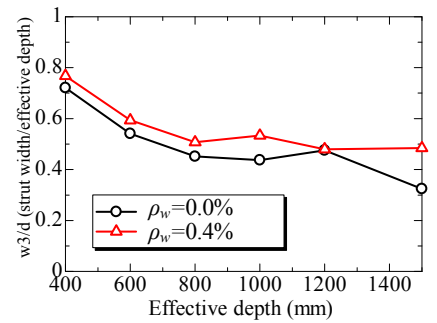

(d) Position: $x_{3} / a=0.8$

Fig. 23 Relation between compression strut width and beam effective depth. $x_{1}, x_{2}, x_{3}$ and $a$ are the distances to the center of loading plate and shear span length, respectively. $w_{1} / d, w_{2} / d$ and $w_{3} / d$ are the compression strut width divided by beam effective depth. 


\section{Conclusions}

In this study, the mechanism of the size effect on the shear strength of RC deep beams, with the shear span to depth ratio of 1.5 , the heights of 400 to $1500 \mathrm{~mm}$ and stirrup ratio of 0.0 to $0.4 \%$, was numerically investigated by using the 3D RBSM. The mechanism was discussed based on the analysis of shear resistance components, i.e., beam and arch actions, and the localized information (crack patterns, the diagonal crack width, and the compressive stress in axial direction), whose detailed evaluation was a highlighted advantage of the 3D RBSM. Finally, the following conclusions were drawn:

1. It was validated that the $3 \mathrm{D}$ RBSM is capable of simulating the shear failure behaviors and reproducing the reinforcing effect of stirrups of large RC deep beams on the scales of around $1000 \mathrm{~mm}$ height.

2. Based on the simulation results for the $\mathrm{RC}$ deep beams with and without stirrups, at the shear span to depth ratio of 1.5 and the effective depths of 400 to $1500 \mathrm{~mm}$, it was found that the normalized shear strength exhibits the same degree of the size dependence regardless of the use of stirrups. Moreover, the degradation of the normalized shear strength is significant for the beams with relatively small heights, smaller than $1000 \mathrm{~mm}$, whereas the slope of degradation gradually becomes gentle with the beam height increase.

3. According to the results of shear resistance components for the RC deep beams, it was revealed that the majority of the shear strength is provided by the arch action (approximately 90\% for the considered cases), and that the reduction of the shear strength with the beam size increase results from the reduction due to the arch action. Although the use of stirrups can improve the grade of the truss action, it has no influence on the grade and the size dependence of the arch action.

4. The major reason for the size effect on the arch action is evaluated by the size dependence of the concrete compressive resultant $C_{c}$ on beam cross sections. It was found that the diagonal crack width in the compression strut at the maximum loading stage gradually becomes bigger if the beam effective depth increases, and that this reduces the compressive strength of the concrete in strut, especially on the sections located nearby loading point $(x / a<0.2)$, i.e., crushing failure zone of concrete, which is suggested as the major mechanism of the size effect on the concrete compressive resultant $C_{c}$.

5. It was showed that the size effect on the arch action is not affected by stirrup amount, in the condition that stirrup ratio is at the level of $0.4 \%$ or lower. This is due to the fact that the change of stirrup amount has no influence on the increasing trend of diagonal crack width with beam effective depth.

6. It was also found that the diagonal crack width not only affects the normalized shear strength, but also has an influence on the post-peak behavior of RC deep beam. In other words, in the cases of beams without stirrups, the higher the beam, the sharper the peak load drop. This indicates a more brittle failure behavior, due to the increasing diagonal crack width. In contrast, if stirrups are used, the sudden sharp widening behavior of the diagonal crack at the post-peak stage can be effectively confined, and the brittle failure behavior can be prevented to a great extent.

7. From the investigation on the size effect in the width of compression strut, it was confirmed that the width of compression strut does not show great change at the locations nearby loading point and mid-height zone in strut. In other words, the size effect on compression strut width probably aggravate the size effect in shear for RC deep beam, but it is not the dominant factor.

\section{Acknowledgments}

This study was funded by the National Natural Science Foundation of China (grant number 51908248) and the Natural Science Foundation of Jiangsu Province (grant number BK20180620).

\section{References}

ACI, (2015). "Building code requirements for reinforced concrete, (318M-14)." American Concrete Institute.

An, X., Maekawa, K. and Okamura, H., (1997). "Numerical simulation of size effect in shear strength of RC beams." Journal of Concrete structures and Pavements, JSCE, 564(V-35), 297-316.

Bažant, Z. P. and Yu, Q., (2005a). "Designing against size effect on shear strength of reinforced concrete beams without stirrups: I. Formulation." J Struct Eng, 131(12), 1877-1885.

Bažant, Z. P. and Yu, Q., (2005b). "Designing against size effect on shear strength of reinforced concrete beams without stirrups: II. Verification and calibration." J Struct Eng, 131(12), 1886-1897.

Bolander, J. E. and Hong, G. S., (2002). "Rigid-body-spring networks modeling of prestressed concrete members." ACI Struct J, 99(5), 595-604.

Cervenka, J., Cervenka, V. and Laserna, S., (2014). “On finite element modeling of compressive failure in brittle materials.” In: N. Bicanic, H. Mang, G. Meschke and R. de Borst Eds., Computational Modelling of Concrete Structure, London: Taylor and Francis Group, 273-281.

CEN, (2014). "Eurocode 2-Design of concrete structures: Part 1-1: General rules and rules for buildings (EN 1992-1-1:2014)." Brussels Belgium: Comité Européen de Normalisation.

Collins, M. P., Vecchio, F. J. and Mehlhorn, G., (1983). "An international competition to predict the response of reinforced concrete panels." Can J Civ Eng, 12, 624-644. 
fib, (2013). "fib model code for concrete structures 2010." Berlin Germany: fib.

fib, (1990). "Model code 90 (Bulletin d'information)" fib, 205-206.

Frosch, R. J., (2000). "Behaviour of large-scale reinforced concrete beams with minimum shear reinforcement." ACI Struct J, 97(6), 814-820.

Fu, L., Nakamura, H., Furuhashi, H., Yamamoto, Y. and Miura, T., (2017a). "Mechanism of shear strength degradation of a reinforced concrete column subjected to cyclic loading." Struc Concr, 18, 177-188.

Fu, L., Nakamura, H., Yamamoto, Y. and Miura, T., (2017b). "Investigation of influence of section pre-crack on shear strength and shear resistance mechanism of RC beams by experiment and 3-D RBSM analysis." Journal of Advanced Concrete Technology, 15(11), 700-712.

Fu, L., Nakamura, H., Yamamoto, Y. and Miura, T., (2020). "Effect of various structural factors of shear strength degradation after yielding of RC members under cyclic loads." Journal of Advanced Concrete Technology, 18(4), 211-226.

Gedik, Y. H., Nakamura, H., Yamamoto, Y. and Kunieda, M., (2011). "Analysis of compression failure of concrete by three dimensional rigid body spring model." Cem Concr Compos, 33, 978-991.

Gedik, Y. H., Nakamura, H., Yamamoto, Y., Ueda, N. and Kunieda, M., (2012). "Effect of stirrups on the shear failure mechanism of deep beams." Journal of Advanced Concrete Technology, 10(1):14-30.

Gunawan, D., Okubo, K., Nakamura, T. and Niwa, J., (2020). "Shear capacity of RC beams based on beam and arch actions." Journal of Advanced Concrete Technology, 18(5), 241-255.

Iguro, M. and Shioya, T., (1985). "Experimental studies on shear strength of large reinforced concrete beams under uniformly distributed load." Concrete Library of JSCE, 5, 137-154.

JSCE, (2017). "Standard specifications for Concrete-Design." Tokyo: Japan Society of Civil Engineering.

Kani, G. N. J., (1967). "How safe are our large reinforced concrete beams?" Journal of American Concrete Institute, 64(3), 128-141.

Kobayashi, H., Unjoh, S. and Salamy, M. R., (2005), "Experimental evaluation of shear strength for large scale deep beam." Proceedings of the Japan Concrete Institute. 27(2), 829-834. (in Japanese)

Kosa, K., Kobayashi, H., Uchida, S. and Nishioka, T., (2009). "Experimental and analytical studies on size effect in RC deep beam." Journal of JSCE, A65(2), 368-383. (in Japanese)

Kuchma, D., Végh, P., Simionopoulos, K., Stanik, B. and Collins, M. P., (1997). "The influence of concrete strength, distribution of longitudinal reinforcement, and member size, on the shear strength of reinforced concrete beams." In: Concrete tension and size effect - Utilisation of concrete tension in structural concrete design and relevance of size effect, CEB Bulletin 237, Lausanne: $f i b$, pp 258.

Leonhardt, F. and Walther, R., (1962). "Schubversuche an Einfeldrigen Stahlbeton-Balken mit und ohne Schubbewehrung zur Ermittlung der Schubtragfähigkeit und der Oberen Schubspannungsgrenze." Heft 151, Deutcher Ausschuss für Stahlbeton, Berlin: W. Ernst, u. Sohn, 66. (in German)

Lertsrisakulrat, T, Niwa, J. and Yanagawa, A., (2002). "Concepts of localized compressive failure of concrete in RC deep beams.” Journal of JSCE, 697, 215-225.

Lubell, A., Sherwood, T., Bentz, E. C. and Collins, M. P., (2004). "Safe shear design of large, wide beams." Concrete International, 26(1), 67-78.

Miura, T., Sato, K. and Nakamura, H. (2020). "The role of microcracking on the compressive strength and stiffness of cracked concrete with different crack widths and angles evaluated by DIC." Cement and Concrete Composites, 114, 1-10.

Miyahara, T., Kawakami, T. and Maekawa, K., (1987). "Nonlinear behavior of cracked reinforced concrete plate element under uniaxial compression." Journal of JSCE, 378, 249-258. (in Japanese)

MOHURD, (2015). "Code for design of concrete structures (GB 50010-2010, including GB 50010-2015 Revison)." Ministry of Housing and Urban Notice No. 743, AQSIQ-China.

Nakamura, H., Iwamoto, T., Fu, L., Yamamoto, Y., Miura, T. and Gedik, Y. H., (2018). "Shear resistance mechanism evaluation of RC beams based on arch and beam actions." Journal of Advanced Concrete Technology, 16(11), 563-576.

Nakamura, H., Nanri, T., Miura, T. and Roy, S., (2018). "Experimental investigation of compressive strength and compressive fracture energy of longitudinally cracked concrete." Cem Concr Compos, 93, 1-18.

Shioya, T., Iguro, M., Nojiri, Y., Akiayma, H. and Okada, T., (1990). "Shear strength of large reinforced concrete beams, fracture mechanics: application to concrete." In: V. C. Li, Y. Zdenek, P. Bazant, Eds., Fracture Mechanics: Application to Concrete (ACI SP-118), Farmington Hill MI: American Concrete Institute, 259-276.

Suga, M., Nakamura, H., Higai, T. and Saito, S., (2001). "Effect of bond properties on the mechanical behavior of RC beam." Proceedings of the Japan Concrete Institute, 23(3), 295-300. (in Japanese)

Tang, C. Y. and Tan, K. H., (2004). "Interactive mechanical model for shear strength of deep beams." Journal of Structural Engineering, 130(10), 1534-1544.

Tan, K. H., Cheng, G. H. and Cheong, H. K., (2005). "Size effect in shear strength of large beams-behaviour and finite element modelling." Magazine of Concrete Research, 57(8), 497-509.

Teng, S., Kong, F. K., Poh, S. P., Guan, L. W. and Tan, K. H., (1996). "Performance of strengthened concrete deep beams predamaged in shear." ACI Structural Journal, March-April, 159-171. 
Tung, N. D. and Tue, N. V., (2016). “A new approach to shear design of slender reinforced concrete members without transverse reinforcement." Eng Struct, 107, 180-94.

Walraven, J. and Lehwalter, N. (1994). "Size Effects in Short Beams Loaded in Shear." ACI Structural Journal, 91(5), 585-593.

Yamada, Y., (2019). “An analytical study on interactions of artificial cracks and holes Contributing to increases in the shear strengths of RC beams." Journal of Advanced Concrete Technology, 17(10), 579-591.

Yamamoto, Y., Nakamura, H., Kuroda, I. and Furuya, N., (2008). "Analysis of compression failure of concrete by three-dimensional rigid body spring model." Journal of JSCE, 64(4), 612-630. (in Japanese)

Yamamoto, Y,. Nakamura, H. Kuroda, I. and Furuya, N., (2010). "Analysis of uniaxial compression failure of confined concrete by three dimensional rigid body spring model." Journal of JSCE, 66(4), 433-451. (in Japanese)

Yamamoto, Y., Nakamura, H., Kuroda, I. and Furuya, N., (2014). "Crack propagation analysis of reinforced concrete wall under cyclic loading using RBSM." European Journal of Environmental and Civil Engineering, 18(7), 780-792.

Yu, Q. and Bažant, Z. P., (2011). "Can stirrups suppress size effect on shear strength of RC beams?" J Struct Eng, 137(5), 607-617.

Zararis, P. D. and Papadakis, G. Ch., (2001). "Diagonal shear failure and size effect in RC beams without web reinforcement." J Struct Eng, 127(1), 733-742.

Zhang, N. and Tan, K. H., (2007). "Size effect in RC deep beams: Experimental investigation and STM verification." Eng Struc, 29(12), 3241-3254. 